\title{
Coordinated observations of sprites and in-cloud lightning
}

\section{flash structure}

Gaopeng Lu, ${ }^{1,2}$ Steven A. Cummer, ${ }^{1}$ Jingbo Li ${ }^{1,3}$ Lucian Zigoneanu, ${ }^{1}$ Walter A. Lyons, ${ }^{4}$ Mark A. Stanley, ${ }^{5}$ William Rison, ${ }^{5}$ Paul R. Krehbiel, ${ }^{5}$ Harald E. Edens, ${ }^{5}$

Ronald J. Thomas, ${ }^{5}$ William H. Beasley, ${ }^{6}$ Stephanie A. Weiss, ${ }^{6}$ Richard J. Blakeslee, ${ }^{7}$

Eric C. Bruning, ${ }^{8}$ Donald R. MacGorman, ${ }^{9}$ Tiffany C. Meyer, ${ }^{10}$ Kevin Palivec, ${ }^{11}$

Thomas Ashcraft, ${ }^{12}$ and Tim Samaras ${ }^{13,14}$

Received 31 October 2012; revised 28 March 2013; accepted 25 April 2013; published 26 June 2013.

[1] The temporal and spatial development of sprite-producing lightning flashes is examined with coordinated observations over an asymmetric mesoscale convective system (MCS) on 29 June 2011 near the Oklahoma Lightning Mapping Array (LMA). Sprites produced by a total of 26 lightning flashes were observed simultaneously on video from Bennett, Colorado and Hawley, Texas, enabling a triangulation of sprites in comparison with temporal development of parent lightning (in particular, negatively charged stepped leaders) in three-dimensional space. In general, prompt sprites produced within $20 \mathrm{~ms}$ after the causative stroke are less horizontally displaced (typically $<30 \mathrm{~km}$ ) from the ground stroke than delayed sprites, which usually occur over $40 \mathrm{~ms}$ after the stroke with significant lateral offsets $(>30 \mathrm{~km})$. However, both prompt and delayed sprites are usually centered within $30 \mathrm{~km}$ of the geometric center of relevant LMA sources (with affinity to negative stepped leaders) during the prior $100 \mathrm{~ms}$ interval. Multiple sprites appearing as dancing/jumping events associated with a single lightning flash could be produced either by distinct strokes of the flash, by a single stroke through a series of current surges superposed on an intense continuing current, or by both. Our observations imply that sprites elongated in one direction are sometimes linked to in-cloud leader structure with the same elongation, and sprites that were more symmetric were produced above the progression of multiple negative leaders. This suggests that the large-scale structure of sprites could be affected by the in-cloud geometry of positive charge removal. Based on an expanded dataset of 39 sprite-parent flashes by including more sprites recorded by one single camera over the same MCS, the altitude (above mean sea level, MSL) of positively charged cloud region tapped by sprite-producing strokes declined gradually from $\sim 10 \mathrm{~km} \mathrm{MSL}\left(-35^{\circ} \mathrm{C}\right)$ to around $6 \mathrm{~km} \mathrm{MSL}$ $\left(-10^{\circ} \mathrm{C}\right)$ as the MCS evolved through the mature stage. On average, the positive charge removal by causative strokes of sprites observed on 29 June is centered at $3.6 \mathrm{~km}$ above the freezing level or at $7.9 \mathrm{~km}$ above ground level.

Citation: Lu, G., et al. (2013), Coordinated observations of sprites and in-cloud lightning flash structure, J. Geophys. Res. Atmos., 118, 6607-6632, doi:10.1002/jgrd.50459.

\section{Introduction}

[2] Understanding of lightning effects in near Earth's space has progressed substantially by studying associated transient luminous events (TLEs) in the mesosphere

\footnotetext{
${ }^{1}$ Electrical and Computer Engineering Department, Duke University, Durham, North Carolina, USA.

${ }^{2}$ Now at Key Laboratory of Middle Atmosphere and Global Environment Observation, Institute of Atmospheric Physics, Chinese Academy of Sciences, Beijing, China.

${ }^{3}$ Now at Intel Corporation, Hillsboro, Oregon, USA.

Corresponding author: G. Lu, Key Laboratory of Middle Atmosphere and Global Environment Observation, Institute of Atmospheric Physics, Chinese Academy of Sciences, Beijing 100029, China. (gaopenglu@gmail.com)

(C)2013. American Geophysical Union. All Rights Reserved. 2169-897X/13/10.1002/jgrd.50459
}

[Rodger, 1999; Pasko et al., 2011; Rycroft and Harrison, 2011]. As one major class of TLEs, sprites are produced by cloud-to-ground (CG) strokes, overwhelmingly positive polarity [Boccippio et al., 1995; Lyons, 1996; Huang et al., 1999] and occasionally negative [Barrington-Leigh et al.,

\footnotetext{
${ }^{4}$ FMA Research Inc., Fort Collins, Colorado, USA.

${ }^{5}$ Langmuir Laboratory, New Mexico Institute of Mining and Technology, Socorro, New Mexico, USA.

${ }^{6}$ School of Meteorology, University of Oklahoma, Norman, Oklahoma, USA

${ }^{7}$ Marshall Space Flight Center, NASA, Huntsville, Alabama, USA.

${ }^{8}$ Department of Geosciences, Texas Tech University, Lubbock, Texas, USA.

${ }^{9}$ National Severe Storm Laboratory, Norman, Oklahoma, USA

${ }^{10}$ Warning Decision Training Branch, National Weather Service, Norman, Oklahoma, USA.

${ }^{11}$ Hawley, Texas, USA.

${ }^{12}$ Heliotown Observatory, Lamy, New Mexico, USA.

${ }^{13}$ Samaras Technologies, Bennett, Colorado, USA.

${ }^{14}$ Deceased 31 May 2013.
} 


\section{LU ET AL.: SPRITE TRIANGULATION NEAR OKLMA}

1999; Taylor et al., 2008; Li et al., 2012], that transfer a large amount of charge from cloud to ground through an impulse current following the return stroke [Gomes and Cooray, 1998; Bell et al., 1998; Cummer and Lyons, 2005] and/or a tailing continuing current that endures tens to hundreds of milliseconds [Cummer and Füllekrug, 2001]. The fast charge removal from clouds generates a transient electric field in the mesosphere [Pasko et al., 1997], which can exceed threshold for conventional dielectric breakdown to initiate the streamer-type ionization [Pasko et al., 1998a, Raizer et al., 1998; Liu and Pasko, 2004; Ebert et al., 2010; Qin et al., 2011] to span the altitude range of 40 to $90 \mathrm{~km}$ [Sentman and Wescott, 1993; Lyons, 1994; Stanley et al., 1999; McHarg et al., 2002].

[3] Observations from a variety of platforms including airplanes [Sentman and Wescott, 1993] and orbiting vehicles [Vaughan et al., 1992; Boeck et al., 1995; Yair et al., 2004; Chen et al., 2008], with coordinated measurements of electrical properties of causative strokes [Reising et al., 1996; Cummer and Inan, 1997; Li et al., 2008], have enriched our understanding of the phenomenology of sprites and advanced the exploration of their correlation with parent lightning. Sprites typically appear as brief, vertically structured optical emissions above energetic thunderstorms abundant in high peak-current +CG strokes [Winckler, 1995; Neubert et al., 2001]. Most sprites compose multiple column- or carrot-shaped elements that each usually remains luminous less than the integration time (usually $\sim 17 \mathrm{~ms}$ ) of a regular-rate video field [Sentman and Wescott, 1993; Sentman et al., 1995; São Sabbas et al., 2003], although individual sprite elements may remain visible for $>40 \mathrm{~ms}$ if the driving electric field is sustained by continuing lightning charge transfer. Within the resolution available to imaging systems, sprites may consist of multiple elements that appear simultaneously (as "sprite clusters") over a transverse scale of 10 to $50 \mathrm{~km}$ [Sentman and Wescott, 1993; Sentman et al., 1995; Füllekrug et al., 2001] or sequentially (as "jumping" or "dancing" sprites) over lateral distances up to $200 \mathrm{~km}$ [Lyons, 1994; Winckler et al., 1996].

[4] Coordinated observations also demonstrate considerable variations in the temporal and spatial relationship between sprites and causative strokes. Time delays of sprites relative to parent strokes range widely from $<1 \mathrm{~ms}$ to more than $200 \mathrm{~ms}$ with the majority recorded within $20 \mathrm{~ms}$ after the return stroke [Hu et al., 2002; Li et al., 2008]. Sprites are often laterally displaced from the ground location of parent strokes, and the horizontal offset can vary from essentially zero to as much as $100 \mathrm{~km}$ [Sentman et al., 1995; Lyons, 1996; Füllekrug et al., 2001; Wescott et al., 2001; Soula et al., 2010], implying the influence of some factors that are not reflected in most sprite models in addition to a long, tortuous lightning channel with a significant horizontal section [Fuquay, 1982].

[5] The observed variations in sprite morphology and the spatial and temporal relationship between sprites and causative strokes reflect the complexity of parent lightning in addition to the possible influence of micrometeors [Wescott et al., 2001; Zabotin and Wright, 2001] or mesospheric inhomogeneity [Sentman et al., 2003]. It has been suggested that in-cloud (IC) activity of sprite-producing $+\mathrm{CG}(\mathrm{SP}+\mathrm{CG})$ strokes could play a role in sprite formation [Valdivia et al., 1997; Ohkubo et al., 2005; van der Velde et al., 2006; Marshall et al., 2007; Asano et al., 2009b]. For example, measurements have shown that at least in some cases, the IC activity is connected to a simultaneous enhancement in cloud-to-ground charge transfer [Li et al., 2008] that modeling shows can produce a sprite [Yashunin et al., 2007; Asano et al., 2009a]. There is also numerical modeling showing that sprites formation laterally displaced from parent strokes and some variances in sprite morphology might be caused by a horizontal incloud lightning channel [Asano et al., 2009b]. To understand how the in-cloud lightning structure affects the sprite morphology, it is necessary to make complementary observations of lightning development with considerable temporal and spatial resolution in addition to sprite observations, as first implemented by Stanley [2000] near the Lightning Detection and Ranging system in Florida.

[6] The main objective of this work is to investigate the connection between sprites and their parent lightning on the basis of coordinated sprite and lightning observations near Lightning Mapping Arrays (LMAs). A network of low-light video cameras (SpriteCam) has been installed across the United States to capture TLEs with an emphasis over the U.S. Great Plains, where mesoscale convective. systems (MCSs) are proficient in producing sprites during the mature and dissipation stage [Lyons, 1996; Lyons et al., 2009]. Building on prior studies of lightning mapping observations related to sprites or high charge transfer positive strokes [Stanley, 2000; van der Velde et al., 2006, 2010; Marshall et al., 2007; Lu et al., 2009; Lang et al., 2010; Suzuki et al., 2011], sprite observations of the SpriteCam network in 2011 near the LMAs are examined to show how the in-cloud lightning structure is linked to the sprite-driving charge transfer and sprite formation in the mesosphere.

[7] Here we focus the main analysis on triangulated sprite observations on 29 June 2011 over an asymmetric MCS near the Oklahoma Lightning Mapping Array (OKLMA) [MacGorman et al., 2008], with some discussions extended to other sprites observed over the same storm. Sprite production along with its spatial and temporal variations is compared with the flash structure shown by LMA data and time-resolved lightning current extracted from broadband lightning sferics. By triangulating sprites with multiple cameras relative to the LMA-resolved lightning structure and measuring electrical lightning properties with a wide range of radio instrumentation, we investigate the relationship between sprite occurrence and causative lightning development. The main conclusions regarding the MCS on 29 June are summarized in the following:

[8] 1. Analyses of sprite observations on 29 June confirm that the impulse charge moment change (iCMC) is a better metric than peak current to evaluate the sprite production potential. For the MCS on 29 June, the parent flash of $+\mathrm{CG}$ strokes with iCMCs $>+300 \mathrm{C} \mathrm{km}$ is $90 \%$ likely to produce a sprite at some point during the flash.

[9] 2. Multiple sprites can be produced in a lightning flash in two distinct ways. In 8 out of 14 cases, multiple sprites are produced by discrete strokes widely separated in the flash; in the remaining six cases, multiple sprites are produced through impulse charge transfer and intermittent surges during the continuing current in one stroke.

[10] 3. Sprites are usually produced above the cloud region tapped by preceding negative leaders even if the sprite 


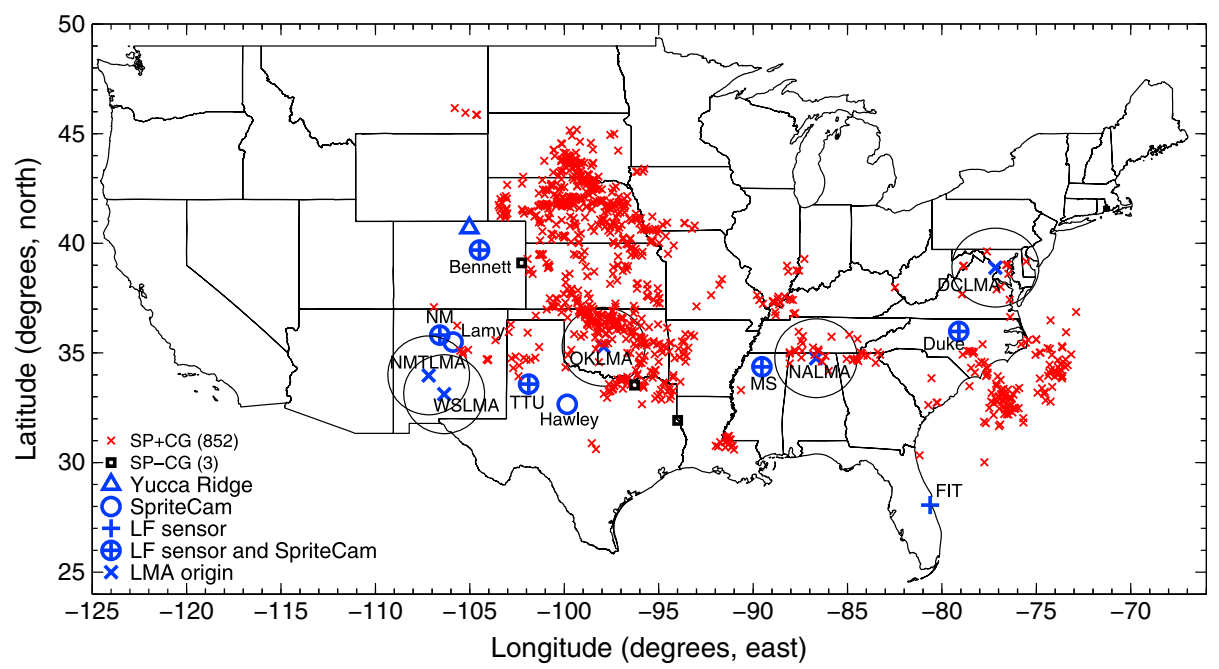

Figure 1. Instrumentation network for the sprite observations in 2011. Low-light video cameras (SpriteCam) and low-frequency (LF) magnetic sensors are installed at several stations to investigate the correlation between transient luminous events and their parent lightning in the U.S. High Plains, especially those near the Lightning Mapping Array (LMA) in New Mexico (New Mexico Tech LMA and White Sands LMA), Oklahoma, north Alabama, and Washington, DC. The circles centered at LMA origins represent the $200 \mathrm{~km}$ detection range. The Yucca Ridge Field Station $\left(40.702^{\circ} \mathrm{N},-105.030^{\circ} \mathrm{E}\right)$ near Fort Collins, Colorado, coordinates the operation of SpriteCams. Positive and negative sprite-producing strokes are shown as red crosses and black squares, respectively.

is considerably displaced from the parent stroke. Although we observed horizontal offsets as large as $70 \mathrm{~km}$ from the ground stroke, especially for sprites with long delays ( $>40 \mathrm{~ms}$ ), sprites are typically centered laterally within $30 \mathrm{~km}$ of the cloud region explored by negative leaders within $100 \mathrm{~ms}$ prior to the sprite.

[11] 4. On average, prompt sprites produced with delays $<20 \mathrm{~ms}$ are less laterally displaced from the parent stroke than delayed sprites that typically occur more than $40 \mathrm{~ms}$ after the stroke. In other words, parent strokes of prompt sprites remove positive charge from less displaced cloud regions than lightning strokes producing delayed sprites.

[12] 5. When the large-scale structure of sprites exhibits significant asymmetry, such as elongation in one direction, the same asymmetry is often shown by in-cloud negative leader progression. This suggests that the large-scale structure of sprites is affected by the geometry of positive charge removal from the in-cloud charge reservoir.

[13] 6. Many sprites, especially those appearing to be very bright, were observed over the secondary maximum of radar reflectivity $(\geq 35 \mathrm{dBZ})$ in the trailing stratiform, indicating the presence of a major positive charge concentration in this region.

[14] 7. Examinations of $42 \mathrm{SP}+\mathrm{CG}$ strokes spawned in 39 flashes indicate that the altitude (above mean sea level, MSL) of positive charge removal by $\mathrm{SP}+\mathrm{CG}$ strokes descended gradually from about $10 \mathrm{~km} \mathrm{MSL}\left(-35^{\circ} \mathrm{C}\right)$ to near $6 \mathrm{~km} \mathrm{MSL}\left(-10^{\circ} \mathrm{C}\right)$ as the MCS evolved through the mature stage.

\section{Instrumentation Network and Methods}

[15] Figure 1 shows the instrumentation network for sprite observations, which consists of seven low-light video cameras (SpriteCam) located near LMAs in New Mexico,
Oklahoma, Alabama, and Washington, DC. In 2011, the SpriteCam network recorded about 900 sprites over a variety of meteorological systems; the vast majority $(>95 \%)$ of sprite-producing strokes were reported by the U.S. National Lightning Detection Network (NLDN) [Cummins et al., 1998; Lyons et al., 2009], including three high peak-current $(>65 \mathrm{kA})$ negative strokes with iCMCs in excess of $-450 \mathrm{C} \mathrm{km}$ [Li et al., 2012]. The ground locations of NLDN-detected sprite-parent strokes are shown in Figure 1. Lightning emissions of $<1 \mathrm{~Hz}$ to $300 \mathrm{kHz}$ are recorded for these strokes with multiple magnetic sensors near Duke University $\left(35.970^{\circ} \mathrm{N},-79.094^{\circ} \mathrm{E}\right)$. Lowfrequency (LF) signals are recorded at five more sites, making it possible to detect lightning processes on 10 to $100 \mu \mathrm{s}$ timescales in sprite-parent flashes that are not reported by the NLDN. Broadband lightning emissions recorded for sprites not linked to NLDN-reported lightning events suggest a correlation with $+\mathrm{CG}$ strokes; there is no convincing evidence that the sprite might be produced by IC lightning processes. All our measurements (as well as NLDN and LMA) are synchronized using the Global Positioning System (GPS).

\subsection{Low-Light Video Systems (SpriteCam)}

[16] Under favorable cloud-free conditions, large-scale brief luminous glows from sprites are readily captured by imaging devices with enhanced sensitivity [Franz et al., 1990], and those particularly bright might be visible to dark-adapted naked eyes [Lyons, 1994]. The SpriteCam is developed based on a high-sensitivity monochrome CCD video camera (WAT-902H2U, with minimum illumination of 0.0001 lux at F1.4), which is mounted on an antenna rotator for a maneuverable operation to maximize the yield by manually pointing it toward the sky portion of possible TLE observation. This is assisted by a nowcast webpage that 
shows locations of high-iCMC strokes based on real-time NLDN data and the lightning Charge Moment Change Network with two magnetic sensors near Yucca Ridge and Duke University, respectively [Lang et al., 2010].

[17] The SpriteCam is operated in trigger mode (based on the UFOCaptureV2 software, http://sonotaco.com/soft/e index. html\#ufocv2) to capture sprites with brightness above a threshold related to the background brightness. Video streams over $2 \mathrm{~s}$ roughly centered at the triggering event are saved at a rate of 30 frames (or 60 interlaced fields) per second. A time inserter overlays the GPS-based Coordinated Universal Time (UTC) with millisecond precision on each video field. As the stamped time corresponds to the end-of-field, the captured sprite initiates in the preceding $\sim 17 \mathrm{~ms}$ (the integration time of one field) and presumably after the causative stroke. When a sprite becomes brighter in the next field, the stamped time roughly corresponds to the sprite initiation because highspeed imaging indicates that sprites typically develop to the full vertical scale within a few milliseconds after inception [Rairden and Mende, 1995; Stanley et al., 1999; McHarg et al., 2002]. Previous analyses have shown that the vast majority of sprites initiate within $20 \mathrm{~ms}$ after parent strokes [Li et al., 2008], as confirmed by SpriteCam observations in 2011. In this work, sprites initiated within $20 \mathrm{~ms}$ after the initial ground contact of causative strokes are defined as prompt events and otherwise are delayed events that occur mainly by responding to the enhancement in continuing current [Gamerota et al., 2011].

[18] When video observations of sprites are available from two or more stations, sprite locations can be triangulated by analysis with respect to the background star field [Wescott et al., 2001; Suzuki et al., 2011]. In particular, when the multiple elements of a sprite appear in sequence, it is possible to triangulate individual elements in comparison with the progression of lightning leaders inside clouds (see an example in section 5.2). Different sprite elements that appear in the same video field are distinguished and triangulated with the assumption that the brighter element recorded by one camera will appear brighter when observed by another. We estimate the transverse scale of sprites with the vertically structured streamers, which will underestimate the overall size of high-altitude optical emissions when the sprite is accompanied by a diffuse halo [Wescott et al., 2001]. Also, different SpriteCams are not synchronized, and recorded sprite images are usually not perfectly matched in time, which might lead to small uncertainty (a few $\mathrm{km}$ ) in triangulation since the optically visible size of sprites might vary with time.

\subsection{Lightning Mapping Array (LMA)}

[19] Lightning development in the electrified thunderclouds comprises negative and positive leaders that start from a common origin and extend into cloud regions charged oppositely to their respective polarity [Kasemir, 1960; Coleman et al., 2003]. Due to the stepped nature [Morrow and Blackburn, 2002], progression of negative leaders through positive cloud regions are prolific in very high frequency (VHF) emissions. Lightning sources of these impulsive emissions can be located via measurements at multiple ground-based receivers using the "time-of-arrival" technique [Proctor, 1971], such as the Lightning Mapping Array (LMA) developed by New Mexico Tech [Rison et al., 1999; Thomas et al., 2004]. Positive leaders through negatively charged cloud regions are less impulsive, while their trails can be resolved by detecting associated retrograde negative breakdown (so-called "recoil leaders" or $K$ processes) when they encounter localized negative charge concentrations [Thomas et al., 2001; Akita et al., 2010]. Therefore, the LMA-resolved lightning structure provides an alternative way to construct the gross charge structure of thunderclouds in addition to balloon soundings of electric field profile [Winn et al., 1981; Stolzenburg et al., 1998; Coleman et al., 2003; Carey et al., 2005; Rust et al., 2005; Bruning et al., 2010].

[20] With GPS-synchronized measurements at multiple VHF receivers, the LMA locates isolated sources in successive $80 \mu$ s time windows and yields three-dimensional (3-D) images of lightning evolution with considerable temporal and spatial resolution [Rison et al., 1999]. LMA observations contain clues regarding key stages of lightning evolution in the parent storm. For example, initial LMA sources in a sequence are used to locate the flash origin between two oppositely charged cloud regions where the electric stress exceeds the threshold of lightning initiation [Coleman et al., 2003; Maggio et al., 2005].

[21] As the results of our analysis are subject to the LMA detection efficiency, we mainly examined the evolution of sprite-producing strokes located within $200 \mathrm{~km}$ of the LMA origin, as suggested by previous work using the OKLMA data [MacGorman et al., 2008; Lang et al., 2010]. Our analysis is based on LMA sources that are located by $\geq 8 \mathrm{VHF}$ receivers with reduced chi-square $\left(\chi^{2}\right)$ values $\leq 1.0$. However, as the OKLMA detection efficiency decreases beyond $120 \mathrm{~km}$ [Lang et al., 2010], LMA sources at $>120 \mathrm{~km}$ range detected by seven receivers (with $\chi^{2} \leq 1.0$ ) are included. During the observations on 29 June, an airplane flew over the OKLMA and provided a chance to evaluate the LMA geolocation accuracy [e.g., Thomas et al., 2004]. The aircraft tracking result suggests that the LMA location uncertainty for sources at ranges up to $80 \mathrm{~km}$ is $<500 \mathrm{~m}$, consistent with the analyses of Lang et al. [2010], who showed that the vertical LMA geolocation error is less than $\sim 2 \mathrm{~km}$ for lightning sources within $200 \mathrm{~km}$.

[22] LMA sources that are interpreted as being related to negative leaders are used to identify positively charged cloud regions in sprite-producing storms, which are our major interest. Negative cloud regions are marked with LMA sources linked to $K$ processes, which are characterized by relatively weak VHF radiation, sporadic detections, and relatively small detection range $(<100 \mathrm{~km})$ in contrast with negative stepped leaders [Thomas et al., 2001]. Hence, the majority of LMA sources, especially those detected at $>100 \mathrm{~km}$ range, reflect the progression of negative leaders through positive cloud regions with radar reflectivity $\geq 20 \mathrm{dBZ}$ [Stanley, 2000; Lang et al., 2010]; our analyses did not include LMA sources $>100 \mathrm{~km}$ from the LMA origin that are likely associated with $K$ processes. We use the LMA sources within an empirical time interval of $100 \mathrm{~ms}$ (denoted as $t_{100, \mathrm{sp}}$ ) prior to sprites to visually identify the positive cloud region with major contribution to sprite production. Lang et al. [2010] used a similar method to identify the positive cloud region responsible for sprites with LMA sources detected after the $\mathrm{SP}+\mathrm{CG}$ stroke through the end of TLE observation. Our method usually uses more LMA sources to constrain the positive cloud region possibly 


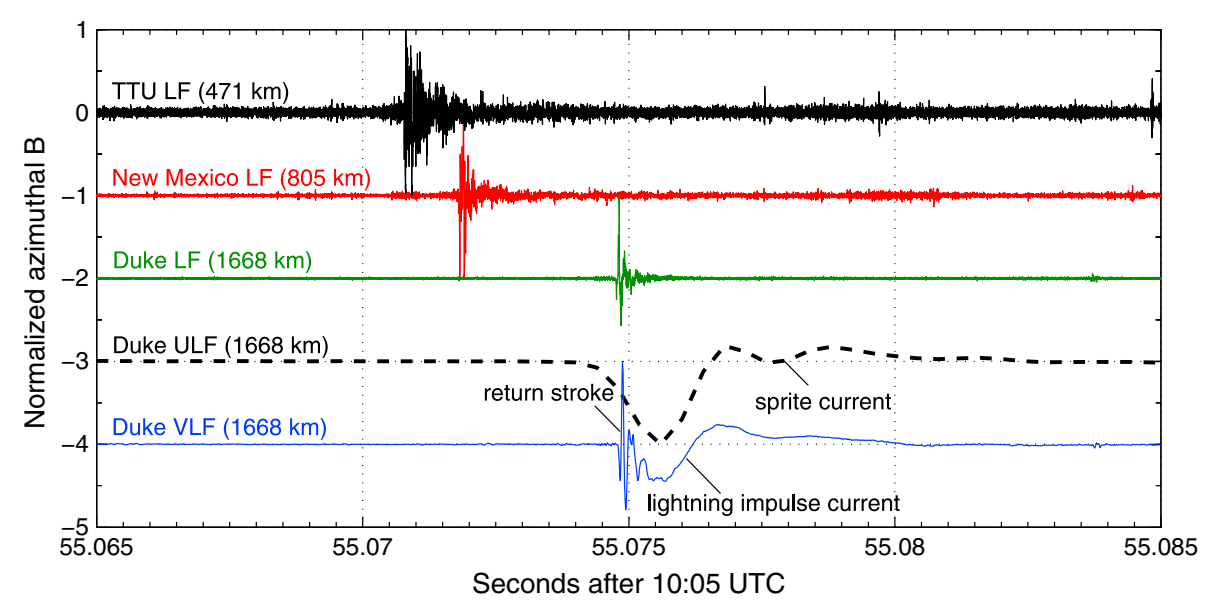

Figure 2. Broadband lightning signals measured with various magnetic sensors for a $+\mathrm{CG}$ stroke (at 1005:55.069 UTC on 29 June) producing a prompt sprite. The signal of sprite current is distinct in Duke ULF and VLF data, indicating that the sprite reached the maximum brightness within 3 ms after the return stroke. The plotted signals are normalized by the maximum and are shifted vertically to avoid the overlap. Absolute UTC times are used for plotting the measured signal; the temporal offset of lightning-induced defections recorded by different sensors reflects varying propagation delays due to different distances from the lightning source.

involved in sprite production by outlining the progression of negative leaders prior to sprites, yet it remains possible our method does not identify the whole cloud region contributing to sprite formation. For the majority of sprites observed on 29 June, two methods yield similar estimates on the altitude of positive charge removal by $\mathrm{SP}+\mathrm{CG}$ strokes. However, in several cases where sprites occurred with short delays $(<10 \mathrm{~ms})$, only a few LMA sources are identified with the method of Lang et al. [2010], which are insufficient to outline the cloud region of positive charge removal. To estimate the average density of charge removal by $\mathrm{SP}+\mathrm{CGs}$, we constrain the positively charged cloud region, as a first-order approximation, using a circle with the minimum diameter to enclose LMA sources (linked to negative leaders propagating in the stratiform) detected after the return stroke through the end of detectable continuing current.

\subsection{Radio Frequency Magnetic Sensors}

[23] All the sferic measurements are synchronized using a GPS receiver with operational accuracy better than $1 \mu \mathrm{s}$, and various sampling rates are used depending on the actual frequency range of different sensors that are coordinated to record lightning emissions in a broad frequency range $(<1 \mathrm{~Hz}$ to $300 \mathrm{kHz}$ ). Both very low frequency (VLF, $50 \mathrm{~Hz}$ to $\sim 30 \mathrm{kHz}$, sampled at $100 \mathrm{kHz}$ ) and ultra low-frequency (ULF, $<1 \mathrm{~Hz}$ to $400 \mathrm{~Hz}$, sampled at $2500 \mathrm{~Hz}$ ) sensors have the long-range detection capability because lightning signals at these frequencies effectively propagate in the Earthionosphere waveguide [Pessi et al., 2009]. These two sensors are deployed in Duke Forest with low background noise level. Lightning emissions in the $\mathrm{LF}(30 \mathrm{kHz}$ to $300 \mathrm{kHz}$, sampled at $1 \mathrm{MHz}$ ) range attenuate fast over distance. Therefore, multiple LF sensors are installed, including one on the campus of Texas Tech University within $500 \mathrm{~km}$ range from most sprites on 29 June. Measurements at three or more LF sensor contribute to locate individual fast lightning events during the sprite-parent flash.
[24] Figure 2 shows the sferic measurements with multiple magnetic sensors for a $+\mathrm{CG}$ stroke that produced a prompt sprite. LF signals recorded at close range can be used to determine the polarity and type (i.e., intracloud or cloud to ground) of lightning events. The polarity of a lightning event can be determined using the initial pulse (i.e., the ground wave) recorded at relatively close range $(<800 \mathrm{~km}$ at nighttime). LF signals of IC fast events usually appear as isolated pulses of short duration $(<50 \mu \mathrm{s})$, and reflections from the ionosphere are often distinct [Smith et al., 1999; Wu et al., 2011]. In contrast, LF emissions of CG strokes usually bear a longer duration $(>100 \mu \mathrm{s})$, and the sferic waveform typically reflects the complexity of source current that is mainly driven by the progression of negative leaders. As shown in Figure 2, the LF sferics of SP+CG strokes usually appear as a burst of impulsive signals over milliseconds, reflecting a connection with post-stroke negative leader propagation along in-cloud lightning channels [Lu et al., 2009]. Similarly, LF signals of negative CGs are often preceded by emissions from downward negative leader prior to the stroke. In general, our approach of lightning classification is more reliable by using the signals of both events and the context.

[25] For the sprite-associated charge transfer investigated in this work, we are particularly interested in the impulse charge transfer within a few milliseconds after the return stroke [Gomes and Cooray, 1998; Bell et al., 1998] and the subsequent continuing current that lasts tens to hundreds of milliseconds [Rust et al., 1981; Li et al., 2008]. In the cylindrical coordinates where the stroke is placed at the origin, the magnetic deflection is dominated by the azimuthal component, $B_{\phi}(t)$. In our definitions, $+\mathrm{CGs}$ that effectively transfer positive charge from cloud to ground generate negative $B_{\phi}(t)$ at the sensor and result in positive charge moment changes.

[26] From the ULF data, we apply the deconvolution method of Cummer and Inan [2000] to derive the time- 

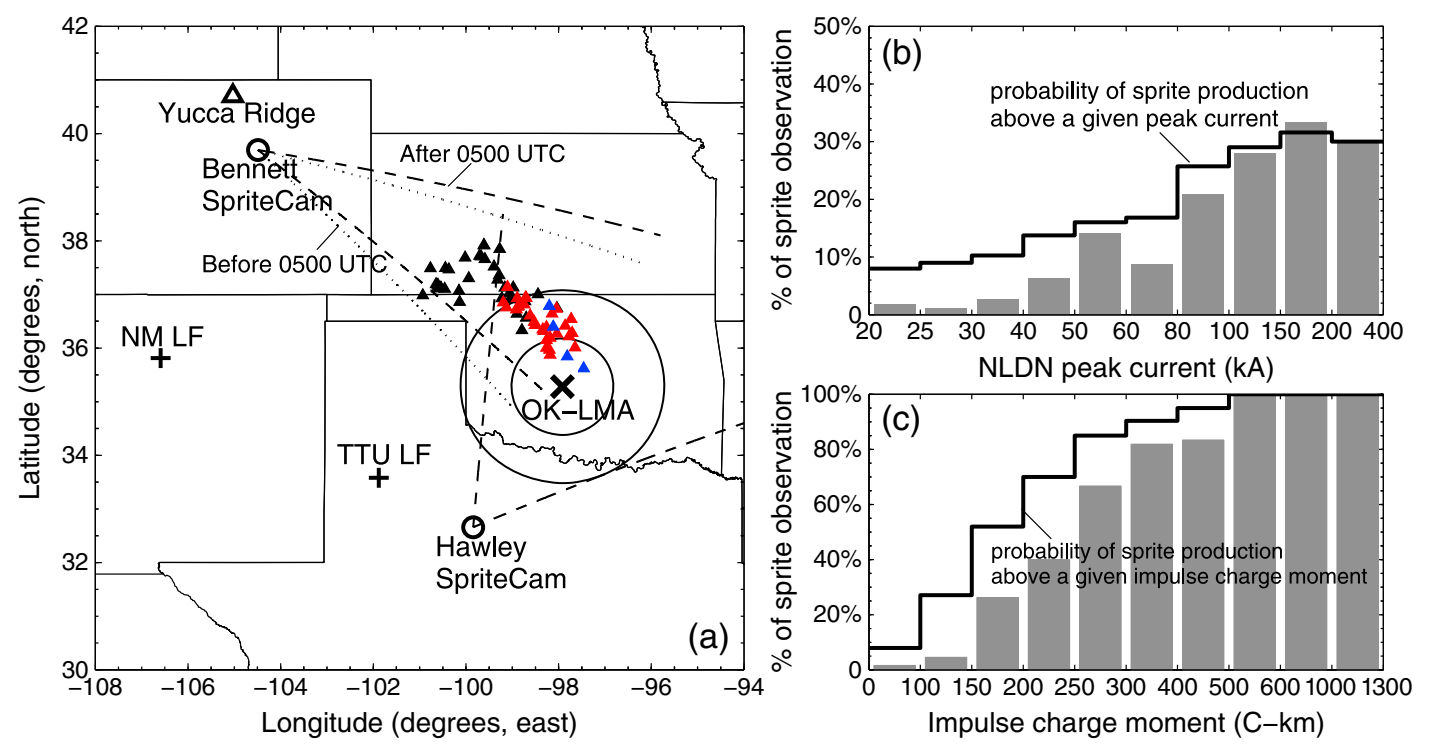

Figure 3. (a) Coordinated sprite-lightning observation near the OKLMA on 29 June 2011. The two circles centered at the LMA origin $\left(35.279^{\circ} \mathrm{N},-97.918^{\circ} \mathrm{E}\right)$ represent the range of $100 \mathrm{~km}$ and $200 \mathrm{~km}$ radius, respectively. Lightning strokes related to sprites captured by both Bennett and Hawley SpriteCams are indicated by red triangles. Parent strokes of sprites only recorded at Bennett or Hawley are indicated by black and blue triangles, respectively. (b) Probability of sprite production for $+\mathrm{CG}$ strokes with peak currents in a given range (bars) and above a given value (line). (c) Probability of sprite production for $+\mathrm{CG}$ strokes with impulse charge moment changes in a given range (bars) and above a given value (line).

resolved current moment, $M_{I}(t)$, along a vertical lightning channel. The iCMC is the integral of $M_{I}(t)$ over the first $2 \mathrm{~ms}$ after the return stroke [Cummer and Lyons, 2005]; and the total charge moment change (CMC) is the integral of $M_{I}(t)$ over the discernible duration of lightning-induced excursion [ $\mathrm{Li}$ et al., 2008; Lu et al., 2009]. The VLF data can be used to derive current moment with higher resolution, while in this work they are used mainly to identify the signature of bright sprites that, either prompt or delayed, drive a magnetic pulse of $\sim 2 \mathrm{~ms}$ without considerable energy above $3 \mathrm{kHz}$ (see an example in Figure 2) [Cummer et al., 1998; Cummer and Füllekrug, 2001], reflecting an electrical current along the streamer region of sprites [Pasko et al., 1998b; Hager et al., 2012]. This characteristic signal, especially the absence of VLF energy, provides an efficient means to detect sprite occurrence in special situations, such as daytime sprites caused by exceptionally large CMCs [Stanley et al., 2000]. The delay of sprite current pulse relative to the parent stroke could be $<1 \mathrm{~ms}$ for large impulse charge transfers, and iCMCs greater than $+800 \mathrm{C} \mathrm{km}$ usually contain contributions from both sprites and parent strokes. In this case, it is not possible to discriminate sprite current from lightning current without additional measurements [e.g., Cummer et al., 2006], but the sprite occurrence can be definitively determined. For the MCS on 29 June, the signal of "sprite current" with aforementioned features is used to infer the sprite occurrence (in the field of view of the Bennett camera but not recorded) associated with a high peakcurrent $(277 \mathrm{kA})+\mathrm{CG}$ stroke at 0352 UTC with an exceptional iCMC of $+1280 \mathrm{C} \mathrm{km}$.

\section{Overview of Sprite Observations on 29 June 2011}

[27] The sprites on 29 June were observed above a warm season mesoscale convective system (MCS) common to the U.S. Great Plains. Late in the day 28 June, the moist air from Mexico became instable in eastern Colorado and grew into a squall line near the border of Kansas and Oklahoma between 00 UTC and 01 UTC (29 June). The squall line gradually evolved upscale into a larger MCS with a leading-line, trailing-stratiform (LLTS) structure, which became prominent after 0600 UTC. The MCS at the mature stage exhibited the features of an asymmetric case [Houze et al., 1990], started to become disorganized after 0800 UTC, and eventually dissipated after sunrise. In general, the isolation of the storm and the cloud-free lines of sight made conditions ideal for the observation from Bennett, Colorado $\left(39.693^{\circ} \mathrm{N},-104.488^{\circ} \mathrm{E}\right)$ and Hawley, Texas $\left(32.657^{\circ} \mathrm{N},-99.844^{\circ} \mathrm{E}\right)$. During a time span of $7 \mathrm{~h}$ from 0330 to 1030 UTC, sprites produced by 67 distinct $+\mathrm{CG}$ strokes were recorded by one or both cameras; the subset of these sprites analyzed in detail is described in section 3.3. Parent strokes of these sprites were reported by the NLDN as having peak currents ranging widely from $8 \mathrm{kA}$ to $274 \mathrm{kA}$. A small fraction (12\%) of these strokes, including three with peak currents over $50 \mathrm{kA}$, were classified as positive ICs but were all actually $+\mathrm{CG}$ strokes based on the LF signal.

\subsection{SpriteCam Observations and Sprite Probability}

[28] Figure 3a shows the locations of NLDN-detected SP $+\mathrm{CG}$ strokes with accuracy better than $600 \mathrm{~m}$ in Oklahoma 

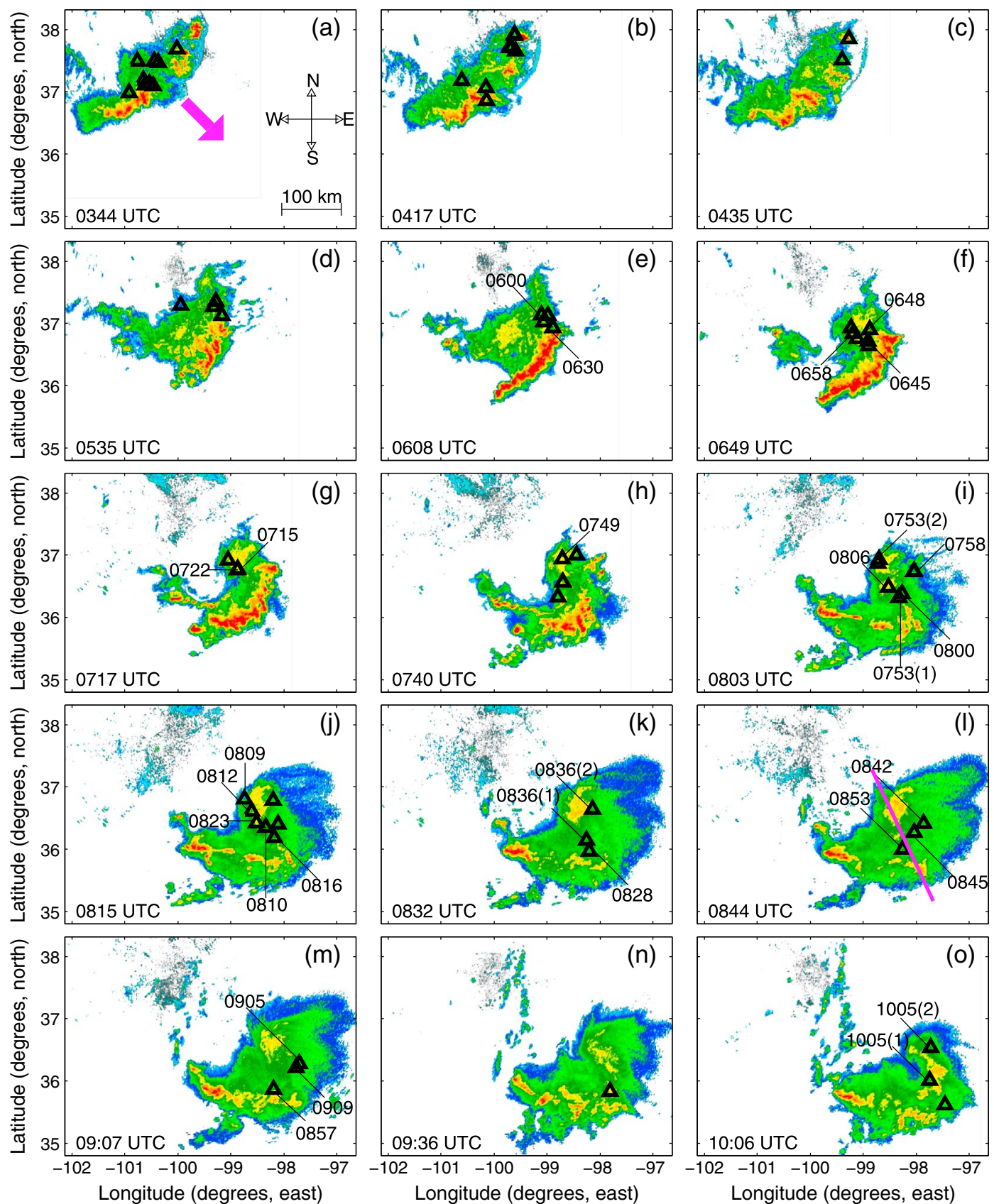

Reflectivity legend (dBZ)

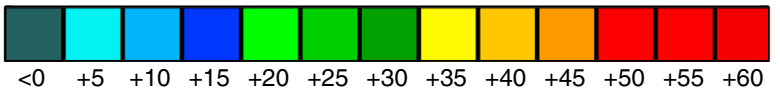

Figure 4. NEXRAD radar scan $\left(0.56^{\circ}\right.$ elevation angle) of base reflectivity from Dodge City, Kansas, showing the evolution of an asymmetric mesoscale convective system over which sprites produced by 67 distinct $+\mathrm{CG}$ strokes were recorded between 0330 UTC and 1010 UTC on 29 June 2011. Parent strokes of these sprites are shown as triangles on the radar image. Most SP+CG strokes were located behind the leading convection line; between 0645 UTC and 0836 UTC, many sprites were observed above a secondary maximum of radar reflectivity $(\geq 35 \mathrm{dBZ})$ embedded in the trailing stratiform. Parent strokes of sprites observed simultaneously from Bennett and Hawley are indicated with the time of occurrence. Figure 5 shows the vertical reflectivity structure of the MCS along a cross section marked by the pink line in Figure 4l, which shows the base reflectivity at 0844 UTC.

[Biagi et al., 2007], and the stroke time can be further determined precisely (to a few $\mu \mathrm{s}$ ) with sferic data. Sprites produced by a total of 29 strokes (spawned in 26 flashes) were recorded by both cameras for a triangulation; there were three flashes that each generated two distinct $\mathrm{SP}+\mathrm{CG}$ strokes. Apparently, the main sprite production after the first capture at 0336 UTC has been tracked by the Bennett SpriteCam, which, due to imperfectness of the imaging 


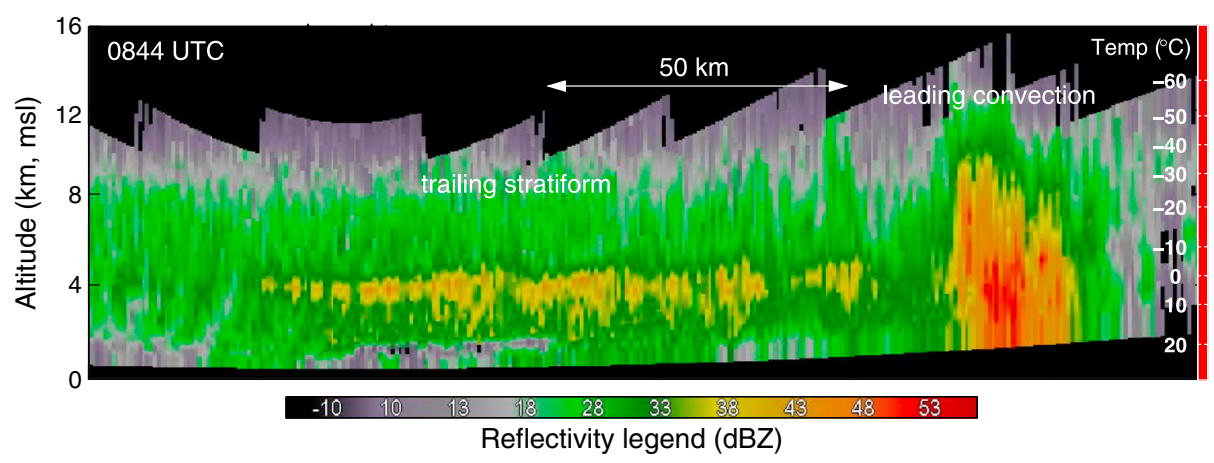

Figure 5. Composite radar scan showing the vertical reflectivity structure (along the pink line shown in Figure 41) of the MCS on 29 June 2011. Note that the reflectivity legend is different from that used in Figure 4 due to the processing with different software.

system, missed the sprites of four strokes recorded at Hawley. The Hawley SpriteCam started to capture sprites at about 0600 UTC when the sprite-producing cells migrated southeastward into the field of view (FOV) and missed several sprites that mostly appeared to be dim as seen from Bennett. At different ranges from the OKLMA, the Bennett and Hawley cameras are mounted with lenses of different focal lengths $(14.0 \mathrm{~mm}$ and $6.0 \mathrm{~mm}$, respectively) so that their horizontal FOV (between dashed lines in Figure 3a) yields comparable coverage over the OKLMA. As shown in Figure 3a, these two cameras are well separated and constitute an ideal pair to triangulate TLEs over central Oklahoma. The average ground level near the OKLMA is about $400 \mathrm{~m}$ [Lang et al., 2010].

[29] Figures $3 b$ and $3 c$ give the percentage of sprite production for about $900+\mathrm{CG}$ strokes (detected by the NLDN with peak currents $>20 \mathrm{kA}$ and located in the FOV of one or both cameras) generated by the MCS on 29 June. These figures give the probability of $+\mathrm{CG}$ strokes, ordered respectively by peak current and impulse charge moment change, to produce a sprite at a certain moment during the parent lightning flash. For example, $+\mathrm{CG}$ strokes with peak currents between $100 \mathrm{kA}$ and $150 \mathrm{kA}$ are $28 \%$ likely to produce sprites, which is almost the same as that for all the +CG strokes with peak currents above $100 \mathrm{kA}$; +CG strokes with iCMCs of $200-250 \mathrm{C} \mathrm{km}$ are $40 \%$ likely to produce sprites, in comparison with $70 \%$ for all the + CGs with iCMCs $>+200 \mathrm{Ckm}$. Our results are consistent with previous assertions of Huang et al. [1999] and Hu et al. [2002] that impulse charge moment is a better metric (than the peak current of return stroke) to assess the potential of a $+\mathrm{CG}$ stroke to produce sprites. Collectively, for the MCS on 29 June, + CG strokes with iCMCs $+300 \mathrm{C} \mathrm{km}$ are $90 \%$ likely to produce sprites during the remaining duration of parent flashes, consistent with the finding of Lyons et al. [2009] that the chance of sprite production is $>75-80 \%$ for + CGs with iCMCs above $+300 \mathrm{C} \mathrm{km}$.

\subsection{Stroke Locations and Storm Structure}

[30] Figure 4 plots the locations of sprite-producing strokes in comparison with the MCS development shown by the plan position indicator of base reflectivity at $0.56^{\circ}$ elevation from the NEXRAD radar located in Dodge City, Kansas. Sprites coincidently recorded at Bennett and Hawley are indicated with the time of their occurrence. At the time of the first sprite observation, the MCS had developed a contiguous radar echo $(>10 \mathrm{dBZ})$ area larger than $20,000 \mathrm{~km}^{2}$, one of the established prerequisites for probable sprite-producing storms in the U.S. High Plains; nearly all the SP+CG strokes were located under cloud regions with modest reflectivity of 20-35 dBZ [Lyons et al., 2009]. Also, after the trailing-stratiform region was formed at about $0530 \mathrm{UTC}$, most $\mathrm{SP}+\mathrm{CG}$ strokes were located behind the arc-shape leading edge with deep convection, confirming previous findings that sprites are commonly observed over the stratiform area of mature LLTS MCSs [Lyons et al., 2009; Lang et al., 2010].

[31] For the MCS on 29 June, roughly between 0600 UTC and 0930 UTC, there was a secondary maximum of radar reflectivity $(\geq 35 \mathrm{dBZ})$ embedded in the stratiform. Most sprites between 0645 UTC and 0836 UTC were observed over this region. Figure 5 shows the vertical cross section of radar reflectivity (composite from multiple NEXRAD radar scans) along the pink line in Figure 4l; the leading convection and trailing stratiform are both distinct. We can see that the enhanced radar echo was related to a bright band (35-45 dBZ) near the freezing level (or $0^{\circ} \mathrm{C}$ isotherm) at $4.7 \mathrm{~km}$ MSL altitude as inferred from the synoptic balloon sounding at $12 \mathrm{UTC}$ from Norman $\left(35.18^{\circ} \mathrm{N},-97.44^{\circ} \mathrm{E}\right)$, Oklahoma. Braun and Houze [1994] attributed the formation of this secondary band to the depositional growth (in the mesoscale updraft of stratiform region) of cloud ice particles detrained from leading convection regions [Carey et al., 2005; Ely et al., 2008]. It is of our particular interest to see if the associated charge separation makes a significant contribution to the abundance of positive charge in favor of sprite production above the trailing stratiform. We will show in section 4.2 that the positive charge layer above this strong radar echo was the main source of the brightest sprite (cluster) observed on 29 June.

\subsection{Selected Sprites for Analysis}

[32] We focus our analysis on the sprites that were coincidently observed from Bennett and Hawley for a triangulation, yet other sprites recorded on one camera remain valuable for the discussion with LMA data in section 7. Triangulated sprites (including 36 temporally and spatially distinct events) were produced by 29 distinct strokes spawned in 26 flashes based on the LMA data. These strokes and sprites are listed in Table 1. The large majority of these strokes were located within $200 \mathrm{~km}$ of the OKLMA 
Table 1. List of SP+CG Strokes (Reported by the NLDN) Associated With Sprites That Were Observed Simultaneously by the Bennett and Hawley SpriteCams on 29 June 2011 Over a Mesoscale Convective System Near the Oklahoma Lightning Mapping Array ${ }^{a}$

\begin{tabular}{|c|c|c|c|c|c|c|c|}
\hline \multirow[b]{2}{*}{ Flash \# } & \multicolumn{4}{|c|}{$\mathrm{SP}+\mathrm{CG}$ Information (From NLDN) } & \multirow{2}{*}{$\begin{array}{c}\mathrm{iCMC} \\
(\mathrm{C} \mathrm{km}) / H_{+\mathrm{SP}} \\
(\mathrm{km}, \mathrm{MSL})\end{array}$} & \multirow[b]{2}{*}{$\begin{array}{c}\mathrm{CMC} \\
(\mathrm{C} \mathrm{km}) / t_{\mathrm{cc}}(\mathrm{ms})\end{array}$} & \multirow[b]{2}{*}{ RS-Sprite Delay } \\
\hline & Time (UTC) & Latitude $\left({ }^{\circ} \mathrm{N}\right)$ & Longitude $\left({ }^{\circ} \mathrm{E}\right)$ & Peak Current (kA) & & & \\
\hline $1^{\mathrm{b}}$ & $06: 00: 57.431$ & 37.1364 & -99.1050 & 79.0 & $290 / 10.0$ & $5000 / 250$ & $\begin{array}{c}t_{\text {delay }} \leq 4 \mathrm{~ms} \\
122 \mathrm{~ms} \leq t_{\text {delay }} \leq 135 \mathrm{~ms}\end{array}$ \\
\hline $2^{\mathrm{b}}$ & $06: 30: 29.667$ & 36.9314 & -98.8921 & 52.0 & $178 / 10.3$ & $6530 / 280$ & $\begin{array}{c}4 \mathrm{~ms} \leq t_{\text {delay }} \leq 15 \mathrm{~ms} \\
287 \mathrm{~ms} \leq t_{\text {delay }} \leq 298 \mathrm{~ms}\end{array}$ \\
\hline $3^{\mathrm{b}}$ & $06: 45: 47.615$ & 36.7183 & -98.9106 & 49.0 & $239 / 10.1$ & $9940 / 400$ & $\begin{array}{c}t_{\text {delay }} \leq 6 \mathrm{~ms} \\
89 \mathrm{~ms} \leq t_{\text {delay }} \leq 106 \mathrm{~ms}\end{array}$ \\
\hline 4 & $06: 48: 49.847$ & 36.7578 & -99.1242 & 63.0 & $541 / 9.5$ & $9930 / 420$ & $t_{\text {delay }} \leq 6 \mathrm{~ms}$ \\
\hline 5 & 06:58:05.647 & 36.8485 & -99.1925 & 87.0 & $595 / 8.9$ & $1800 / 80$ & $t_{\text {delay }} \leq 11 \mathrm{~ms}$ \\
\hline 6 & $07: 15: 10.471$ & 36.7811 & -98.8676 & 36.0 & $115 / 9.6$ & $5440 / 340$ & $6 \mathrm{~ms} \leq t_{\text {delay }} \leq 10 \mathrm{~ms}$ \\
\hline 7 & 07:22:01.783 & 36.7682 & -98.8798 & 65.0 & $580 / 10.7$ & $6190 / 240$ & $t_{\text {delay }} \leq 9 \mathrm{~ms}$ \\
\hline 8 & $07: 49: 14.723$ & 36.9383 & -98.7126 & 106.0 & $661 / 10.3$ & $9120 / 210$ & $t_{\text {delay }} \leq 14 \mathrm{~ms}$ \\
\hline \multirow[t]{2}{*}{$9^{c}$} & 07:53:06.119 & 36.3168 & -98.3247 & 12.0 & $36 / 9.4$ & $3560 / 200$ & $t_{\text {delay }} \sim 17 \mathrm{~ms}$ \\
\hline & 07:53:06.608 & 36.9319 & -98.6983 & 128.0 & $485 / 8.9$ & $5160 / 150$ & $t_{\text {delay }} \leq 12 \mathrm{~ms}$ \\
\hline $10^{\mathrm{b}}$ & 07:58:00.975 & 36.7333 & -98.0445 & 53.0 & $283 / 8.2$ & $11,060 / 470$ & $\begin{array}{c}6 \mathrm{~ms} \leq t_{\text {delay }} \leq 22 \mathrm{~ms} \\
139 \mathrm{~ms} \leq t_{\text {delay }} \leq 151 \mathrm{~ms}\end{array}$ \\
\hline 11 & 08:00:13.429 & 36.3874 & -98.2622 & 18.0 & $28 / 8.4$ & $4800 / 480$ & $50 \mathrm{~ms} \leq t_{\text {delay }} \leq 66 \mathrm{~ms}$ \\
\hline 12 & 08:06:12.016 & 36.4875 & -98.5262 & 100.0 & $349 / 7.3$ & $5860 / 340$ & $5 \mathrm{~ms} \leq t_{\text {delay }} \leq 13 \mathrm{~ms}$ \\
\hline 13 & 08:09:31.720 & 36.8140 & -98.7423 & 156.0 & $1150 / 9.1$ & $7980 / 180$ & $t_{\text {delay }} \leq 14 \mathrm{~ms}$ \\
\hline 14 & 08:10:19.128 & 36.3454 & -98.3419 & 54.0 & $240 / 7.5$ & $7960 / 500$ & $t_{\text {delay }} \leq 6 \mathrm{~ms}$ \\
\hline 15 & 08:12:59.449 & 36.6062 & -98.6129 & 87.0 & $314 / 8.3$ & $11,650 / 550$ & $t_{\text {delay }} \leq 11 \mathrm{~ms}$ \\
\hline $16^{\mathrm{b}}$ & $08: 16: 55.600$ & 36.1907 & -98.1828 & 59.0 & $124 / 7.7$ & $13,000 / 650$ & $\begin{array}{l}122 \mathrm{~ms} \leq t_{\text {delay }} \leq 139 \mathrm{~ms} \\
156 \mathrm{~ms} \leq t_{\text {delay }} \leq 163 \mathrm{~ms} \\
180 \mathrm{~ms} \leq t_{\text {delay }} \leq 188 \mathrm{~ms} \\
272 \mathrm{~ms} \leq t_{\text {delay }} \leq 289 \mathrm{~ms}\end{array}$ \\
\hline 17 & $08: 23: 30.987$ & 36.4296 & -98.5069 & 149.0 & $547 / 7.4$ & $8190 / 400$ & $t_{\text {delay }} \leq 4 \mathrm{~ms}$ \\
\hline 18 & 08:28:53.131 & 36.1486 & -98.2636 & 59.0 & $489 / 8.3$ & $10,360 / 240$ & $t_{\text {delay }} \leq 9 \mathrm{~ms}$ \\
\hline \multirow[t]{2}{*}{$19^{\mathrm{c}}$} & 08:36:11.997 & 35.9678 & -98.1991 & 47.0 & $120 / 7.6$ & $9760 / 460$ & $241 \mathrm{~ms} \leq t_{\text {delay }} \leq 253 \mathrm{~ms}$ \\
\hline & $08: 36: 12.465$ & 36.6425 & -98.1393 & 84.0 & $714 / 6.8$ & $3380 / 80$ & $3 \mathrm{~ms} \leq t_{\text {delay }} \leq 8 \mathrm{~ms}$ \\
\hline 20 & 08:42:39.098 & 36.4155 & -97.8567 & 57.0 & $366 / 5.8$ & $7520 / 180$ & $6 \mathrm{~ms} \leq t_{\text {delay }} \leq 21 \mathrm{~ms}$ \\
\hline 21 & $08: 45: 07.956$ & 36.0038 & -98.2625 & 106.0 & $376 / 7.5$ & $1490 / 180$ & $t_{\text {delay }} \leq 13 \mathrm{~ms}$ \\
\hline 22 & 08:53:17.890 & 36.2677 & -98.0367 & 87.0 & $518 / 6.0$ & $10,200 / 140$ & $1 \mathrm{~ms} \leq t_{\text {delay }} \leq 16 \mathrm{~ms}$ \\
\hline 23 & $08: 57: 26.064$ & 35.8749 & -98.1853 & 51.0 & $180 / 7.4$ & $5780 / 190$ & $t_{\text {delay }} \leq 8 \mathrm{~ms}$ \\
\hline 24 & 09:05:06.400 & 36.2792 & -97.7061 & 136.0 & $602 / 5.9$ & $1430 / 70$ & $t_{\text {delay }} \leq 15 \mathrm{~ms}$ \\
\hline 25 & 09:09:18.922 & 36.2197 & -97.7739 & 103.0 & $591 / 5.4$ & $2640 / 110$ & $1 \mathrm{~ms} \leq t_{\text {delay }} \leq 12 \mathrm{~ms}$ \\
\hline \multirow{2}{*}{$26^{c}$} & $10: 05: 54.428$ & 36.0122 & -97.6457 & 64.0 & $157 / 7.0$ & $4000 / 210$ & $44 \mathrm{~ms} \leq t_{\text {delay }} \leq 55 \mathrm{~ms}$ \\
\hline & 10:05:55.069 & 36.5388 & -97.7274 & 274.0 & $992 / 7.3$ & $4510 / 330$ & $t_{\text {delay }} \leq 5 \mathrm{~ms}$ \\
\hline
\end{tabular}

${ }^{\mathrm{a}}$ Time, location, and peak current are given for the strokes. The impulse charge moment change (iCMC) and total charge moment change (CMC) of SP+CG strokes are calculated from Duke ULF data; the charge moment change caused by the sprite current, if calculable, is deducted from CMC to only reflect the charge transfer in SP+CGs. The source altitude (above mean sea level, MSL) of impulse charge transfer $\left(H_{+\mathrm{SP}}\right)$ is determined from LMA sources during the $t_{100, \text { sp }}$ interval. The duration of continuing current $\left(t_{\mathrm{cc}}\right)$ is inferred from ULF data. The last column gives the range for the temporal delay of sprite initiation relative to the return stroke (RS), as constrained with the observations from two cameras. For example, Flash 1 spawned one SP+CG stroke that produced one prompt sprite (initiated within $4 \mathrm{~ms}$ after the return stroke) and one delayed sprite (between 122 and $135 \mathrm{~ms}$ after the return stroke).

${ }^{\mathrm{b}}$ These flashes produced multiple sprites through the charge transfer in one single stroke, and the current surge (e.g., $M$ components) superposed on the continuing current plays a significant role.

${ }^{\mathrm{c}}$ These flashes generated two distinct $\mathrm{SP}+\mathrm{CG}$ strokes that are well separated in location and time.

(Figure 3a), and good LMA data are available to resolve the spatiotemporal development of sprite-parent flashes after 0646 UTC. Almost all of these sprite-parent flashes endured considerably longer than $1 \mathrm{~s}$ (i.e., the traditional flash duration limit used by the NLDN [Cummins et al., 1998]) and developed a lateral scale in excess of $80 \mathrm{~km}$, with a spatial structure reminiscent of that typically observed for $+\mathrm{CG}$ flashes during the mature and dissipation stage of MCSs [Carey et al., 2005], namely the flash initiates in the leading convection and propagates rearward along a slanting pathway into the trailing stratiform to spawn a SP+CG stroke [Stanley, 2000]. Several sprite-producing flashes, however, initiated in the stratiform area [Lang et al., 2010] and spawned a sprite-producing +CG stroke shortly after flash onset. Measurable continuing current for $\mathrm{SP}+\mathrm{CG}$ strokes was always linked to negative leader progression resolved by the LMA.
[33] The impulse and total charge moment change (over the discernible duration of continuing current, $t_{\mathrm{cc}}$ ) of SP $+\mathrm{CG}$ strokes are calculated from Duke ULF signals recorded at $1720 \pm 80 \mathrm{~km}$ range. The original altitude of positive charge removal $\left(H_{+\mathrm{SP}}\right)$ by $\mathrm{SP}+\mathrm{CGs}$, as estimated with the mean altitude of LMA sources during the $t_{100, \mathrm{sp}}$ interval, is given in Table 1. In order to derive the amount of positive charge removal based on $\mathrm{CMC}$ estimate, one must subtract $H_{+ \text {SP }}$ by the average ground level $(0.4 \mathrm{~km} \mathrm{MSL})$ to get the original altitude of positive charge above ground level (AGL). The values of $H_{+ \text {SP }}$ range between 5.4 and $10.7 \mathrm{~km}$, staying above the freezing level, and most $\mathrm{SP}+\mathrm{CGs}$ with $H_{+ \text {SP }}<7.0 \mathrm{~km}$ were located beneath the stratiform region with $\leq 30 \mathrm{dBZ}$ radar reflectivity. A long continuing current of $>100 \mathrm{~ms}$ is discerned for the vast majority of $\mathrm{SP}+\mathrm{CG}$ strokes, and the average charge moment change is about 
$+6700 \mathrm{C} \mathrm{km}$ (over a mean duration of $\sim 290 \mathrm{~ms}$ ). The average altitude of positive charge depleted through continuing current is assumed to be $H_{+\mathrm{SP}}$, although the altitude of negative leader progression in the stratiform often varies by $1-$ $2 \mathrm{~km}$ [Carey et al., 2005; Lu et al., 2009; Lang et al., 2010]. The positive charge removed through impulse current and continuing current can be calculated by dividing iCMC and $\mathrm{CMC}$ by $\left(H_{+\mathrm{SP}}-0.4 \mathrm{~km}\right)$, respectively. The last column in Table 1 gives the time interval (relative to the return stroke) of sprite initiation as constrained with the observations from two cameras; most sprites were also brightest in these intervals. The dominance of prompt sprites $(25 \mathrm{of}$ 29 strokes or $86 \%$ ) is distinct, including all the $\mathrm{SP}+\mathrm{CG}$ strokes with iCMCs in excess of $+200 \mathrm{C} \mathrm{km}$. Note that for two strokes at $0758 \mathrm{UTC}$ and 0842 UTC, respectively, the maximum delay of sprite initiation inferred from video was slightly over $20 \mathrm{~ms}$, whereas both were treated as prompt events because their iCMCs are above the critical value $(+200 \mathrm{C} \mathrm{km})$ for other prompt sprites on 29 June. Indeed, the signal of sprite current is clear for the case at 0842 UTC, indicating a sprite initiation within $10 \mathrm{~ms}$ after the return stroke.

\section{Case Study of Prompt Sprites}

[34] In this section, we examine the relationship with the parent lightning flash for prompt sprites that occurred within $20 \mathrm{~ms}$ after the causative stroke. Two sprites with distinct brightness are selected for the case study. The first sprite was examined to demonstrate the typical development of sprite-parent flashes on 29 June. Parent flashes of sprites with similar spatial features were examined by Stanley [2000] for a MCS in central Florida. Most sprite-parent flashes after 0820 UTC began as ordinary bilevel IC lightning in the leading convection and propagated northward along a tilted path to lower altitudes in the trailing stratiform, where an intense $\mathrm{SP}+\mathrm{CG}$ stroke was spawned. The second sprite, as the brightest event observed on 29 June, is examined to show that the large-scale geometry of sprite might be affected by in-cloud lightning structure.

\section{1. +CG at 0905:06.400 UTC}

[35] We first present the analysis of a sprite to demonstrate the typical observation on 29 June. This sprite was produced by a $+\mathrm{CG}$ stroke (Flash 24 in Table 1) with a high peak current of $+136 \mathrm{kA}$. Figure 6 shows the OKLMA mapping results and inverted sprite images from the Hawley and Bennett SpriteCam. Observations from two sites constrain the maximum sprite brightness within $15 \mathrm{~ms}$ after the return stroke, and the characteristic signal of sprite current is clear in the VLF waveform, indicating a sprite inception within $3 \mathrm{~ms}$ after the stroke. All the sprite elements are confined in a $40 \mathrm{~km} \times 40 \mathrm{~km}$ region centered with a few kilometers offset from the ground stroke (marked with a pink triangle).

[36] Lightning development associated with this sprite was resolved by as much as $1600 \mathrm{VHF}$ sources (over $2.5 \mathrm{~s}$ ) located within $160 \mathrm{~km}$ of the LMA origin (Figure $6 \mathrm{~b}$ ). The LMA sources from negative leaders are shown with different colors/symbols to illustrate the leader progression over a transverse scale of $>100 \mathrm{~km}$. Figure 6e compared the progression of negative leaders with the radar scan about 2 min after the flash. The flash initiated as ordinary IC near the first LMA source (marked as a cyan cross) located at $8 \mathrm{~km}$ MSL $\left(-20^{\circ} \mathrm{C}\right)$ in the convective region. Negative leaders during the first $350 \mathrm{~ms}$ (blue dots) progressed at $12 \mathrm{~km}$ MSL $\left(-52^{\circ} \mathrm{C}\right)$ near the flash origin, at the expense of negative charge extracted from a negatively charged region mapped by $\sim 300$ LMA sources (black crosses) from recoil leaders [Lu et al., 2011]. The subsequent negative leader progression (green dots) from $\sim 12 \mathrm{~km}$ to $5-7 \mathrm{~km}$ reflects a positive charge layer extending from leading convective line to the trailing stratiform through a slanted transition region [Carey et al., 2005], which is illustrated as an upper positive charge layer in the conceptual model of the charge structure in MCSs [Stolzenburg et al., 1998]. The thickness of this charge layer varies around $2 \mathrm{~km}$ in the conceptual model, which is used in our calculation of average charge removal density by $\mathrm{SP}+\mathrm{CG}$ strokes.

[37] The sprite-producing + CG stroke occurred when negative leaders progressed into the trailing stratiform, probably following a scenario suggested by Krehbiel [1981]: when negative leaders rooted in the leading convection propagate into the stratiform, the elongated lightning channels become cut off due to convective cooling [Picone et al., 1981]; new positive leaders are formed at the other end of forwarding negative leaders (to conserve the charge) and descend toward the ground to culminate a positive stroke under the stratiform. This scenario is consistent with high-speed video observations of +CGs preceded by extensive horizontal lightning channels near the cloud base [Saba et al., 2009], yet coordinated observations of lightning progression inside clouds and leader propagation under the cloud remain desirable to form a comprehensive picture. A +CG stroke occurs to transfer negative charge from ground to cloud (equivalently, transferring positive charge from cloud to ground). The negative charge is first distributed along existing in-cloud lightning channels through impulse current, and then is spread by branched negative leaders into the stratiform through continuing current [Lu et al., 2009].

[38] LMA sources (red dots) within $100 \mathrm{~ms}$ before sprite initiation indicate that negative leaders developed two major extensions in the stratiform region. As indicated in Figure 6b, some of these LMA sources reflect a channel extension indicated by the black arrow, leaving the majority linked to a more extensive in-cloud activity (likely associated with the progression of multiple negative leaders) enclosed by a red circle, over which the sprite was observed. A black plus marks the geometric center of these LMA sources (in the red circle), indicating that the positively charged cloud region with significant contribution to the sprite initiation was centered at $5.9 \mathrm{~km} \mathrm{MSL}\left(-9^{\circ} \mathrm{C}\right)$ in the stratiform.

[39] Figure 7 shows the ULF signal and retrieved current moment for the $\mathrm{SP}+\mathrm{CG}$ stroke, which generated an iCMC of $+602 \mathrm{Ckm}$. The second peak in the current-moment waveform reflects the sprite current, which cumulated a charge moment of $+120 \mathrm{C} \mathrm{km}$. Continuing current in this stroke lasted about $70 \mathrm{~ms}$ and caused more charge moment change $(+830 \mathrm{C} \mathrm{km})$ than the impulse current. As shown in Figure 6b, LMA sources (blue circles) during the continuing current show a modest but definitive expansion of negative leaders in the trailing stratiform [Lu et al., 2009]. Meanwhile, recoil leaders remained active in the negatively charged region of the leading convection. Negative leaders (green circles in Figure 6b) continued spreading for $1.5 \mathrm{~s}$ 

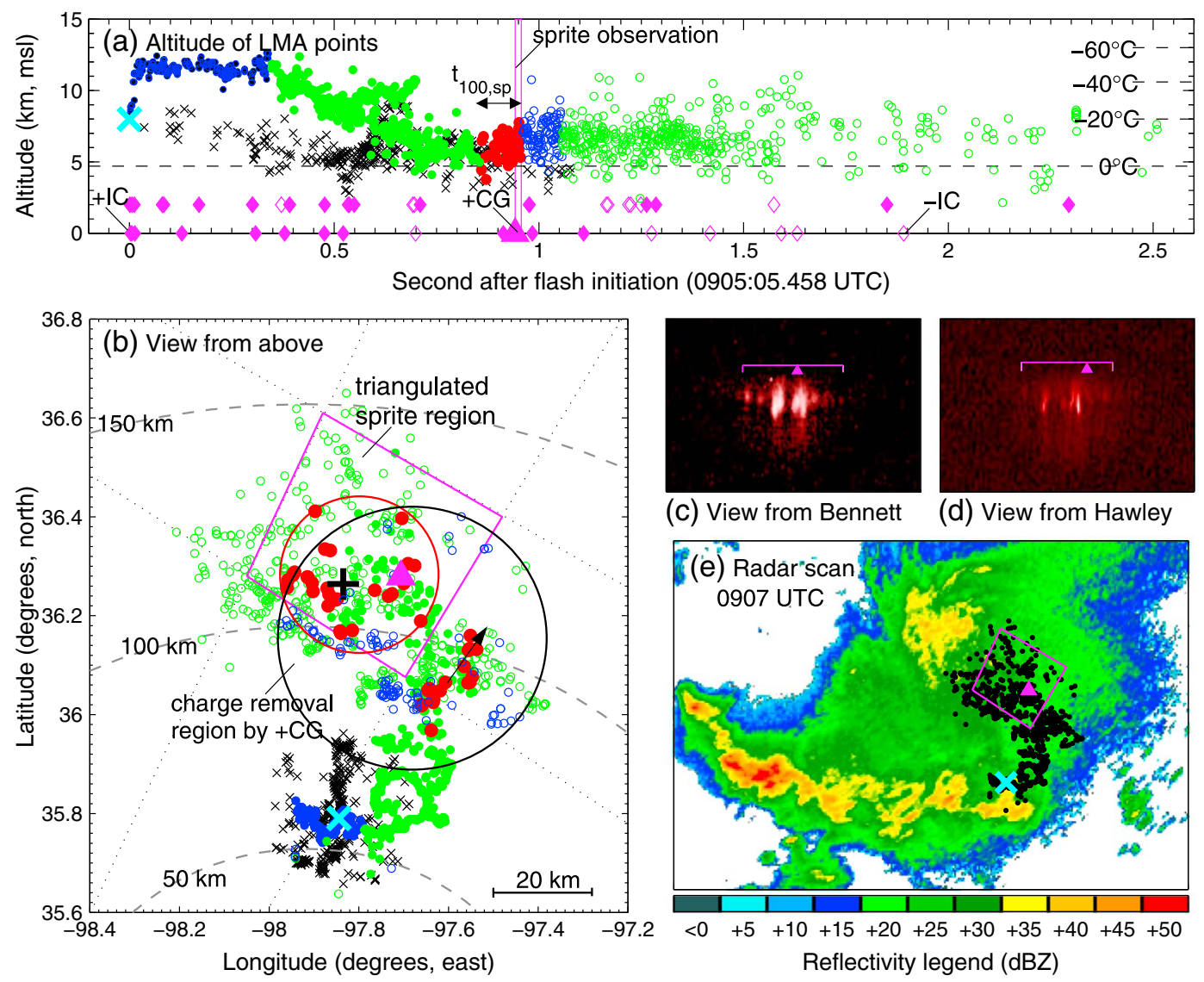

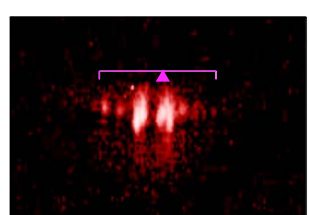

(c) View from Bennett

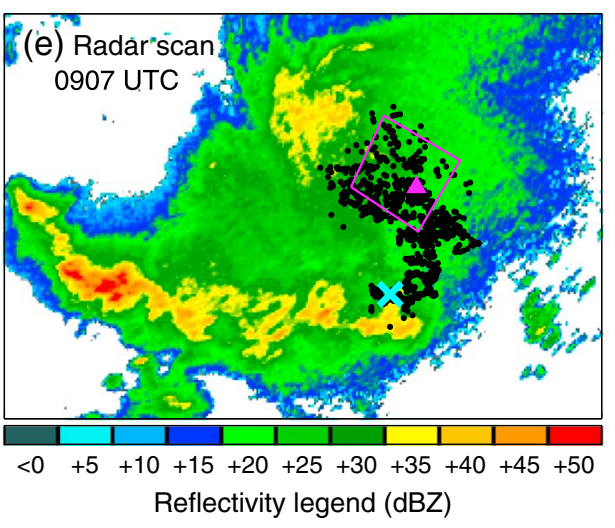

Figure 6. Coordinated sprite-lightning observation of a prompt sprite simultaneously recorded by the Bennett and the Hawley SpriteCams at 0905 UTC on 29 June 2011. (a and b) The time-altitude plot and plan view of LMA sources, respectively. The range rings (centered at the LMA origin) drawn at every $50 \mathrm{~km}$ are shown in Figure 6b. LMA sources related to recoil leaders (or $K$ processes) are marked with black crosses; LMA sources reflecting the propagation of negative leaders are shown as different colors and symbols to illustrate the progression in the convective region (blue dots), along a slanting path from

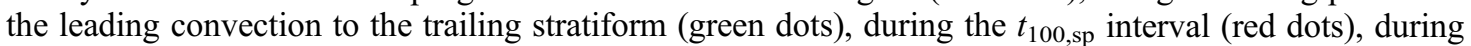
continuing current (blue circles), and after continuing current (green circles). The $+\mathrm{CG}$ stroke is indicated by a pink triangle. IC discharges (solid and open diamonds for positive and negative events, respectively) during the flash are indicated in Figure 6a (lower row for NLDN detections and upper row for more detections with multiple LF sensors). (c and d) The sprite images (with color added to black/white images) from two cameras. (e) The sprite-parent flash (shown by LMA sources for negative leaders) in comparison with the NEXRAD radar scan from Dodge City, Kansas.

after the continuing current dropped below the detectable level, yet remained confined in the stratiform with reflectivity $\geq 20 \mathrm{dBZ}$. Note that the negative leaders did not extend into the cloud region above the secondary maximum of radar reflectivity ( $\geq 35 \mathrm{dBZ}$ ), which is also shown by another sprite-parent flash at 0909 UTC. This suggests that the positive charge density in this region reduced to a level insufficient to sustain the propagation of negative leaders. Indeed, there was a relatively quiet period of sprite observation between 0910 UTC and 1005 UTC, during which only one dim sprite was captured at 0932 UTC. Most + CGs without sprite documented in this interval, including one with iCMC $+200 \mathrm{C} \mathrm{km}$, were associated with similar lightning morphology to those leading to sprites.

[40] The total CMC caused by the $\mathrm{SP}+\mathrm{CG}$ stroke was approximately $+1430 \mathrm{C} \mathrm{km}$, namely, $260 \mathrm{C}$ positive charges were lowered to ground from a cloud region centered at $5.9 \mathrm{~km}$ MSL (or $5.5 \mathrm{~km} \mathrm{AGL).} \mathrm{Our} \mathrm{method}$ using LMA sources during the $+\mathrm{CG}$ stroke constrains the depleted positive charge to a $2 \mathrm{~km}$ thick circular region indicated in Figure 6b. (LMA sources located in the leading convection are not included.) The estimated mean density of positive charge removal by the $\mathrm{SP}+\mathrm{CG}$ stroke is $0.053 \mathrm{nC} / \mathrm{m}^{3}$.

[41] In addition to the $\mathrm{SP}+\mathrm{CG}$ stroke, the NLDN detected 17 fast events (the lower row in Figure 6a) with peak currents below $20 \mathrm{kA}$; at least 32 more fast events (upper row in Figure 6a) from the same flash can be located with sferics recorded at multiple LF sensors. These subsidiary events were all ICs according to broadband sferics recorded at $460 \pm 40 \mathrm{~km}$ range. Nearly one third of these lightning events were of negative polarity, most occurring in the stratiform region after the continuing current. To our best knowledge, as inferred from the 

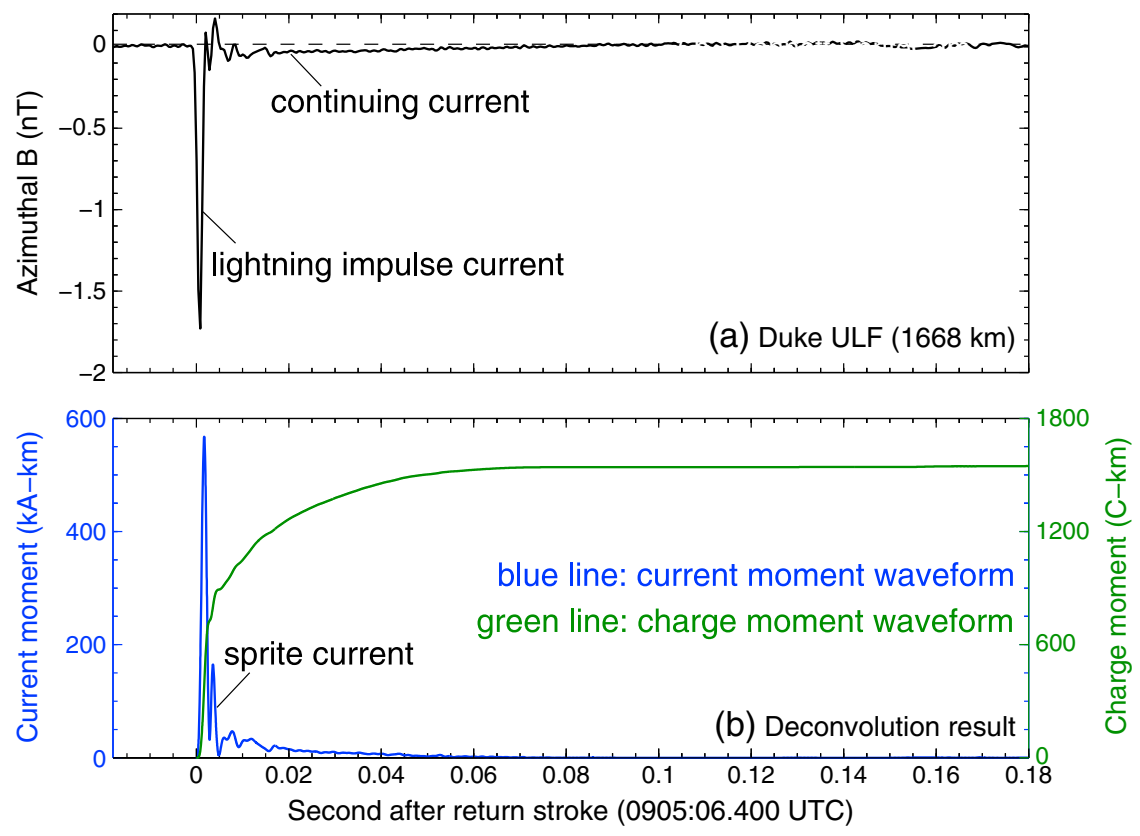

Figure 7. (a) ULF data recorded at $1668 \mathrm{~km}$ range showing the signal of impulse current and continuing current of a SP+CG stroke at 0905:06.400 UTC. (b) Time-resolved current moment and charge moment derived from the ULF data; the second peak in the current-moment waveform reflects the current along streamer regions of the sprite.

time and location of their occurrence, these negative IC events reflect the migration of negative charge (raised from ground through the continuing current) to lower altitudes in the stratiform. It is noticed that the NLDN classified half of these negative ICs as negative CGs (with peak currents $<10 \mathrm{kA}$ ).

\section{2. +CG at 080931.720 UTC}

[42] Here we examine the lightning evolution leading to a $156 \mathrm{kA}+\mathrm{CG}$ stroke (Flash 13 in Table 1) that produced a very bright sprite. As shown in the inset of Figure 8c, the sprite cluster consisted of a total of $\geq 8$ carrot-shape elements, with tendrils extending to altitudes as low as $35 \mathrm{~km}$. The signal of sprite current is distinct in the VLF data, indicating that the sprite was fully formed within $5 \mathrm{~ms}$ after the return stroke and produced a charge moment change around $+150 \mathrm{C} \mathrm{km}$. The observation from Bennett indicates that the sprite production was suppressed on the top at about $85 \mathrm{~km}$, roughly the altitude for nighttime ionosphere at midlatitudes [Han and Cummer, 2010]. As shown in Figure 8d, the sprite was produced over the secondary maximum of radar reflectivity $(\geq 35 \mathrm{dBZ})$ in the stratiform, like most sprites observed between 0640 and 0840 UTC.

[43] The flash initiated near $10 \mathrm{~km}$ (MSL) altitude in the convective region of the MCS, and the subsequent development remained confined in cloud regions with $\geq 20 \mathrm{dBZ}$ reflectivity. As shown in Figure 8a, the negative leader mainly propagated above $7 \mathrm{~km} \mathrm{MSL}\left(-17^{\circ} \mathrm{C}\right)$. During a lifetime of $1.8 \mathrm{~s}$, the flash spawned three $+\mathrm{CG}$ strokes and at least 30 fast IC events that were mostly of positive polarity. Near the end of the flash, several negative IC events occurred in the cloud regions explored by negative leaders (blue circles) during the continuing current, probably in association with negative charge transfer to lower altitudes in the stratiform.

[44] The first stroke (+57 kA) was located below the flash initiation and did not produce a sprite with a moderate iCMC and relatively weak continuing current. The second stroke (not reported by the NLDN) was less impulsive and initiated a continuing current that persisted on a level of $>10 \mathrm{kA} \mathrm{km}$ until a third stroke occurred to produce the sprite; the third stroke is designated as the sprite-producing stroke. The iCMC $(+1150 \mathrm{C} \mathrm{km})$ estimated for this stroke is one of the highest produced by the MCS on 29 June and contains a significant contribution from the sprite current. The exceptional brightness of this sprite might also be linked to a strong continuing current after the third stroke, which stayed on $>70 \mathrm{kA} \mathrm{km}$ for about $20 \mathrm{~ms}$ and lasted up to $200 \mathrm{~ms}$, while the associated negative leaders approached the boundary of $20 \mathrm{dBZ}$ reflectivity. It is also possible that the exceptional brightness of this sprite was aided by the continuing current initiated by the second stroke. The presprite continuing current accumulated a charge moment change of $+4000 \mathrm{C} \mathrm{km}$, which is sufficiently large to alter the status of local mesosphere to a favorable condition for bright sprites.

[45] Note that even with an exceptional brightness, the center of sprite production was clearly offset from the causative stroke. As shown in Figure 8c, LMA sources (red dots in the red circle) during $t_{100, \mathrm{sp}}$, however, indicate that the negative leader progressed (indicated by an arrow) into the cloud region under the sprite. Therefore, this example again shows that the sprite location is linked to the in-cloud negative leader activity prior to the stroke, instead of the stroke itself, confirming that the region of prior negative leader activity is the region where the positive charge is removed by a $\mathrm{SP}+\mathrm{CG}$ stroke. 

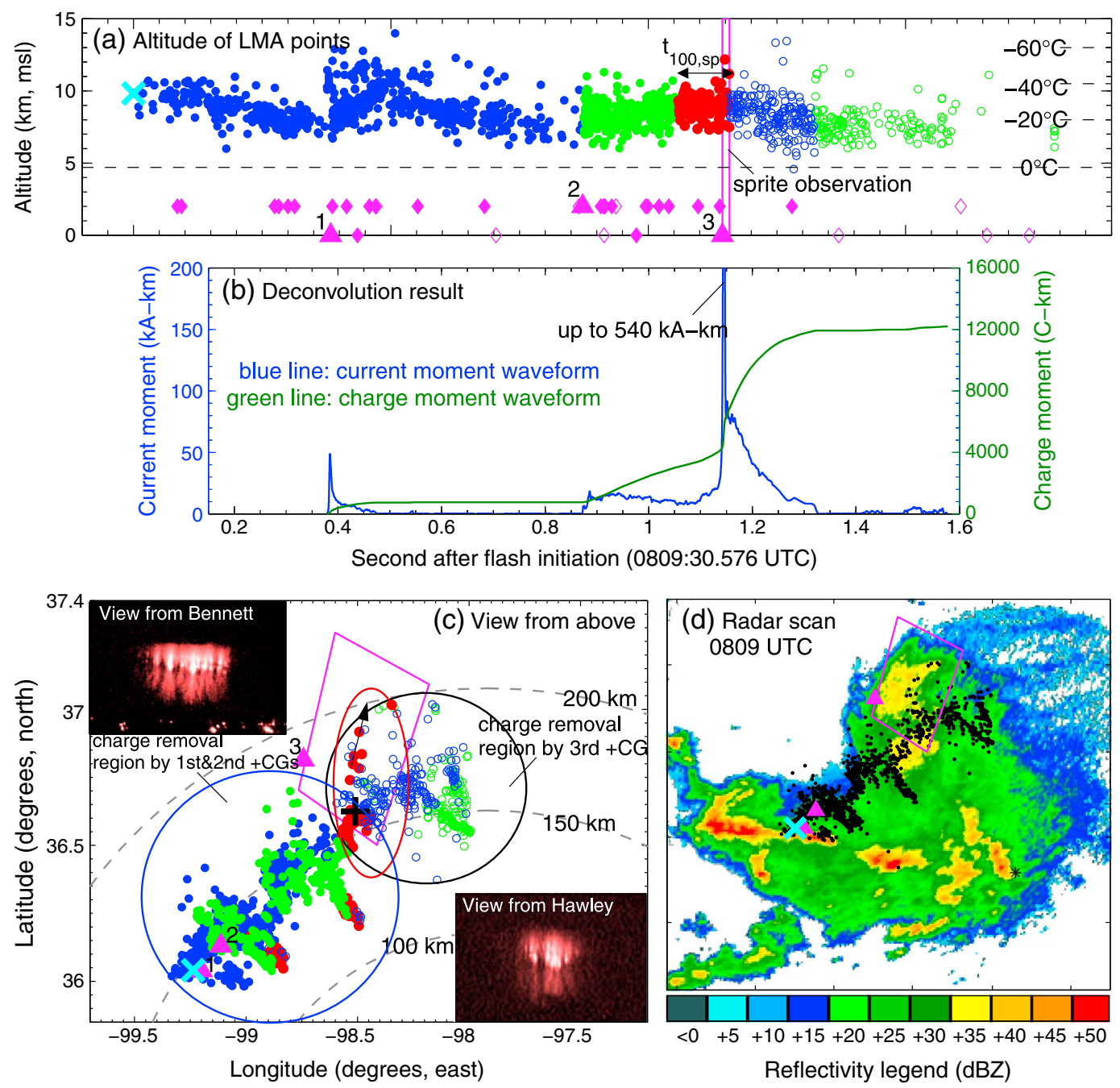

Figure 8. Coordinated observation of a very bright sprite cluster observed at 0809 UTC. (a) Timealtitude plot of LMA sources after the flash initiation near $10 \mathrm{~km}$ MSL altitude in the convection region. (b) Time-resolved current moment and charge moment of the charge transfer to ground during the flash. (c) Horizontal view of the flash structure in comparison with triangulated sprite production (in pink rectangular region). The insets show sprite images from two cameras; city lights are visible at the bottom of the image from Bennett. Note that the sprite production was stretched in the direction (indicated by an arrow) of underneath negative leader propagation during $t_{100, \text { sp. }}$ (d) Comparison between lightning flash structure, triangulated sprite formation, and the radar scan from Dodge City, Kansas, showing that this bright sprite cluster was produced above the secondary maximum of radar reflectivity ( $\geq 35 \mathrm{dBZ})$ in the trailing stratiform.

[46] The geometric center of red dots in the red circle is located at $9.1 \mathrm{~km} \mathrm{MSL}\left(-27^{\circ} \mathrm{C}\right)$ or $8.7 \mathrm{~km}$ above ground level. We assume that all the $+\mathrm{CG}$ strokes in this flash removed charge from a $2 \mathrm{~km}$ deep positively charged layer centered at this altitude. The overall charge moment change caused by three + CGs in this flash was about $+12,000 \mathrm{C} \mathrm{km}$, and thus a total of $1380 \mathrm{C}$ positive charge was transferred to ground. As shown in Figure 8c, the first and second strokes, which together contributed one third of the total charge transfer, removed charge mainly from the cloud region near the flash origin; the average charge removal density by these two strokes is estimated to be $0.027 \mathrm{nC} / \mathrm{m}^{3}$. The third stroke primarily discharged a cloud region above the second maximum of radar reflectivity ( $\geq 35 \mathrm{dBZ})$ in the trailing stratiform, and the average charge removal density is $0.087 \mathrm{nC} / \mathrm{m}^{3}$.
[47] As shown in Figure 8c, the triangulated region of sprite production was stretched (with an aspect ratio of 1.6) in the direction of negative leader progression. This suggests that the spatial geometry, not just the location, of the in-cloud charge removal might have an observable effect on the large-scale structure of sprites, as discussed further in the next section.

\subsection{Triangulation of Prompt Sprites}

[48] Figure 9 shows the triangulation results (relative to the $\mathrm{SP}+\mathrm{CG}$ stroke marked as triangles) for the sprites that initiated within $20 \mathrm{~ms}$ after the return stroke. The subsequent sprites produced by four strokes as delayed events are also shown for a comparison. It should be mentioned that the sprite related to the stroke at 1005:55.069 UTC was capped 

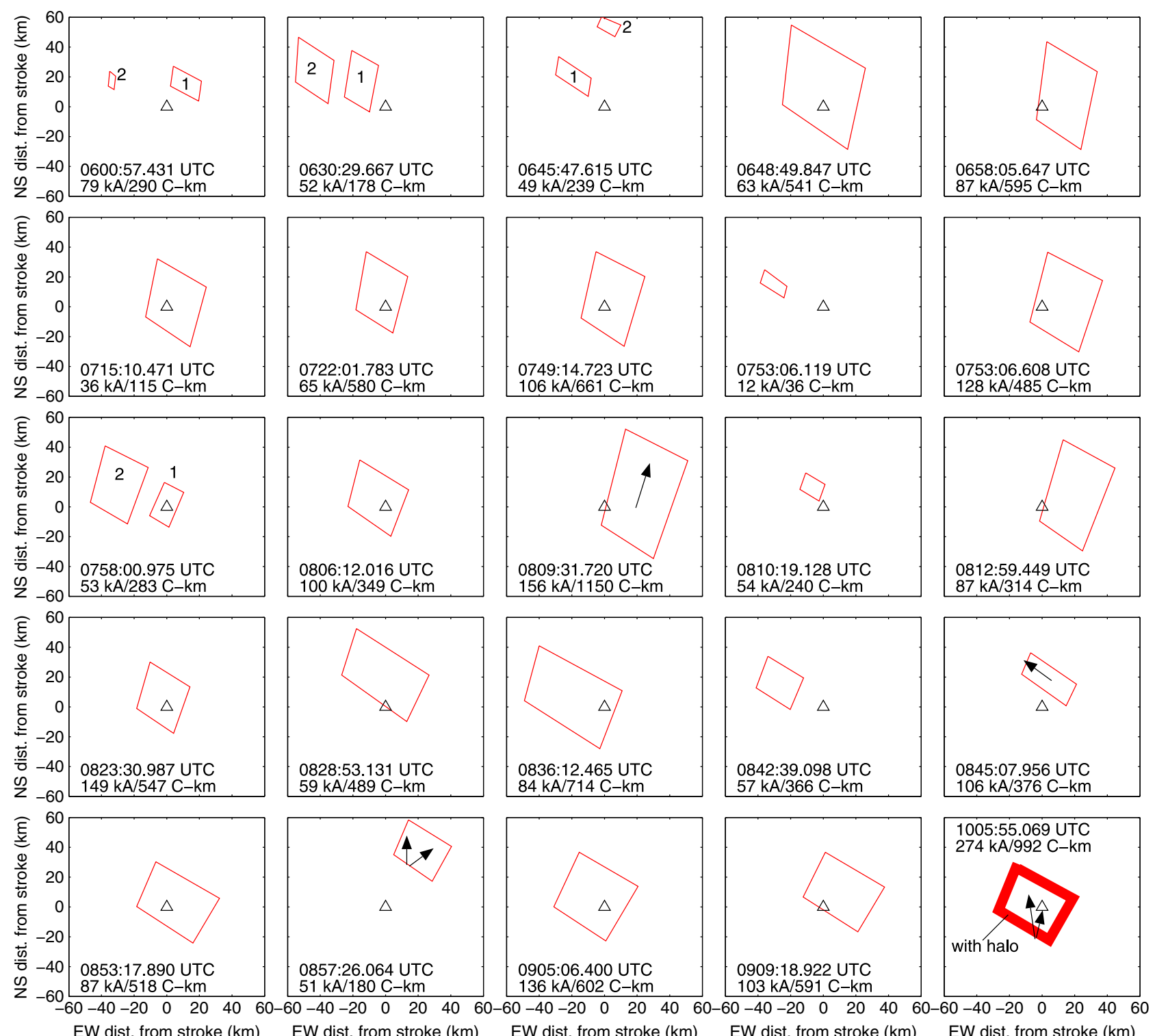

Figure 9. Triangulation of prompt sprites (within $20 \mathrm{~ms}$ after the parent stroke) relative to the parent stroke (indicated by a triangle) with simultaneous observations from Bennett and Hawley. Four SP+CG strokes also produced subsequent sprites (in triangulated region 2) as delayed events. The time, peak current, and iCMC are given for each stroke. For four sprites, the direction of preceding negative leader propagation (indicated with arrows) under the sprite production region is determined from LMA sources during $t_{100, \text { sp. }}$.

by a halo with a transverse scale of $>80 \mathrm{~km}$; the center of this halo was slightly offset $(<10 \mathrm{~km})$ from the ground stroke, which agrees with that halos are almost centered directly above the parent stroke [Wescott et al., 2001], providing a validation of our triangulation results.

[49] Several comments can be made regarding the effect of $\mathrm{SP}+\mathrm{CG}$ strokes on the general morphology of prompt sprites. First of all, there is a tendency that larger iCMCs are more likely linked to horizontally extensive sprites, which is consistent with previous observations that the number of sprites elements is correlated to the magnitude of impulse charge transfer [Adachi et al., 2004; Greenberg et al., 2009]. Among the 13 sprites with one side of the triangulated region $\geq 40 \mathrm{~km}, 11$ events were linked to iCMCs greater than the median $(+485 \mathrm{C} \mathrm{km})$ of the $25+\mathrm{CGs}$ producing prompt sprites. Unfortunately, with the spatial resolution that can be achieved at the range of OKLMA, it is not feasible to determine the exact number of elements for most sprites observed on 29 June.

[50] Secondly, as shown for the sprite examined in section 4.2 , the region of sprite formation is not always of circular symmetry. Instead, it is often elongated in one direction, and the aspect ratio can be as high as 2. Analyses of LMA data for sprites with clear asymmetry indicate that, for two sprites (at 0809 and 0845 UTC), the large-scale sprite structure is stretched in the same direction as the prior negative leader progression; for the remaining events, LMA sources during $t_{100 \text {,sp }}$ are not adequate to outline the presprite negative leader 
progression. Similar analyses for other sprites suggest that a symmetric sprite is likely related to the propagation of multiple leaders, as shown for two events (at 0857 and 1005 UTC) where LMA sources during $t_{100, \text { sp }}$ show the progression of two negative leaders in distinct directions; this probably reflects a more symmetric charge removal. These observations provide evidence that the large-scale sprite structure, particularly its symmetry, is controlled by the geometry of charge removal from the positive reservoir in the cloud. Examinations of more sprite-parent flashes at a closer range $(<100 \mathrm{~km})$ from the LMA origin coordinated with triangulated sprite observations would help verify this more rigorously.

[51] Finally, prompt sprites are seldom centered above the parent ground stroke, although some sprites with apparent lateral offsets from strokes were mainly due to a compact region of sprite production. On average, the center of prompt sprite formation is laterally displaced from the stroke by $17 \mathrm{~km}$. This suggests that the production of prompt sprites is affected by the location of in-cloud charge removal. On the other hand, for these prompt sprites that were mostly associated with iCMCs in excess of $+200 \mathrm{C} \mathrm{km}$, the center of sprite production is typically displaced by $<30 \mathrm{~km}$ from the ground stroke location. There was no observation of horizontal offsets $>50 \mathrm{~km}$ which, as discussed in section 5 , are often observed for delayed sprites on 29 June that typically occurred $>40 \mathrm{~ms}$ after the stroke. A relatively large offset from parent strokes for delayed sprites is actually shown for four strokes that produced both prompt and delayed sprites (Figure 9): in all cases, the delayed sprite was displaced further from the stroke than the prompt sprite.

\section{Case Study of Delayed Sprites}

[52] This section analyzes the in-cloud structure of $+\mathrm{CG}$ strokes producing sprites with a considerable delay (defined as $>20 \mathrm{~ms}$ but typically $>40 \mathrm{~ms}$ ) relative to the return stroke. Three flashes are examined, including a sprite with two elements both laterally displaced by $35-50 \mathrm{~km}$ from the ground stroke (section 5.1), a sprite with six elements (as a "dancing" event) during the continuing current of one stroke (section 5.2), and two sprites produced respectively by distinct strokes in one flash (section 5.3). For these flashes, the LF data were only recorded at two sites (and thus geolocation of fast lightning processes is not feasible), and NLDN-reported lightning events are included in the analysis.

[53] Different from the prompt counterparts, delayed sprites often occur with a substantial lateral offset $(>30 \mathrm{~km})$ from parent strokes. The triangulated sprite formation, however, remains located above the cloud region explored by preceding negative leaders. Therefore, sprites with substantial delays after parent ground strokes occur by responding to in-cloud charge arrangement during continuing current. The offset between the large-scale sprite structure and parent stroke reflects a comparable displacement of the center of positive charge removal relative to the ground stroke.

\section{1. +CG at 0800:13.429 UTC}

[54] Figure 10 shows the analyses of a delayed sprite with two elements (denoted as sp-a and sp-b in Figure 10c) that were relatively faint, but both could be triangulated. Element B appeared to be brighter and persisted longer in the observations from both cameras. The sprite was produced midway through the $0.7 \mathrm{~s}$ lifetime of the parent flash, which was the only sprite-producing flash on 29 June that lasted less than $1 \mathrm{~s}$.

[55] At $>100 \mathrm{~km}$ range from the LMA origin, almost all the LMA sources of this flash were linked to the progression of negative leaders. As shown in Figure 10a, negative leaders propagated in a positive charge region between 7 and $11 \mathrm{~km}$ MSL $\left(-16^{\circ} \mathrm{C}\right.$ to $\left.-44^{\circ} \mathrm{C}\right)$ in the trailing stratiform. The flash origin (cyan cross), as inferred from the first several LMA sources, was located at $6 \mathrm{~km} \mathrm{MSL}\left(-10^{\circ} \mathrm{C}\right)$ in the stratiform (Figure 10d). The spatial structure of this flash is similar to a sprite-parent flash of comparable duration ( $0.9 \mathrm{~s})$ examined by Lang et al. [2010], which also initiated near the freezing level at $4.8 \mathrm{~km}$ (MSL) and discharged a positive charge region centered at $9.3 \mathrm{~km} \mathrm{MSL}\left(-36^{\circ} \mathrm{C}\right)$ in the stratiform of a symmetric MCS.

[56] For this flash with little evolution in the leading convection, the NLDN only reported three fast discharges located within $10 \mathrm{~km}$ of the flash origin, including an early $\mathrm{IC}$ event and two subsequent $+\mathrm{CG}$ strokes. With a relatively small iCMC of $+88 \mathrm{C} \mathrm{km}$, the first stroke initiated a weak but detectable continuing current moment $(<+10 \mathrm{kA}$ $\mathrm{km}$ ). The second stroke, designated as the sprite-causative stroke here, was less impulsive but dramatically boosted the continuing current by a factor of $>3$ (Figure 10b). The continuing current moment retained a magnitude of 20-30 kA km for $>100 \mathrm{~ms}$ and died out slowly toward the end of the flash. As commonly observed for delayed sprites [Gamerota et al., 2011], the sprite was observed around the peak of continuing current when the charge moment change accumulated to $+2400 \mathrm{C} \mathrm{km}$, half of the total CMC of the stroke.

[57] Both sprite elements were laterally displaced by $>30 \mathrm{~km}$ from the causative stroke (Figure 10c). LMA sources in the $t_{100, \text { sp }}$ interval (red dots) indicate that negative leaders propagated near the flash origin and also extended into the cloud region above the second maximum of radar reflectivity ( $\geq 35 \mathrm{dBZ}$ ) embedded in the stratiform (Figure 10d). The main cluster of LMA sources in the red circle is of our major interest since these sources were right below the triangulated sprite and outline the main cloud region of charge removal responsible for sprite production. Positive charge was effectively removed from this region through the intense continuing current, over which the electric field first exceeded the threshold for sprite initiation. Both sprite elements are located $<20 \mathrm{~km}$ from the geometric center (black plus in Figure 10c) of LMA sources in the red circle. The altitude of this geometric center is $8.4 \mathrm{~km} \mathrm{MSL}\left(-24^{\circ} \mathrm{C}\right)$ or $8.0 \mathrm{~km}$ above ground level, which is used as the original height of positive charge removed in this flash (from a $2 \mathrm{~km}$ deep region defined by the black circle). The positively charged region in the stratiform was depleted by approximately $+600 \mathrm{C}$, and the average density of positive charge removal is estimated to be $0.045 \mathrm{nC} / \mathrm{m}^{3}$.

\section{2. +CG at 0816:55.600 UTC}

[58] One of the most enigmatic sprite morphologies is the "jumping/dancing" sprites, in which multiple elements appear intermittently over different regions of the parent storm [Lyons, 1996]. Here we examine a positive stroke (Flash 17 in Table 1) that produced a sequence of six sprite elements through brief surges superposed on a continuing current. 

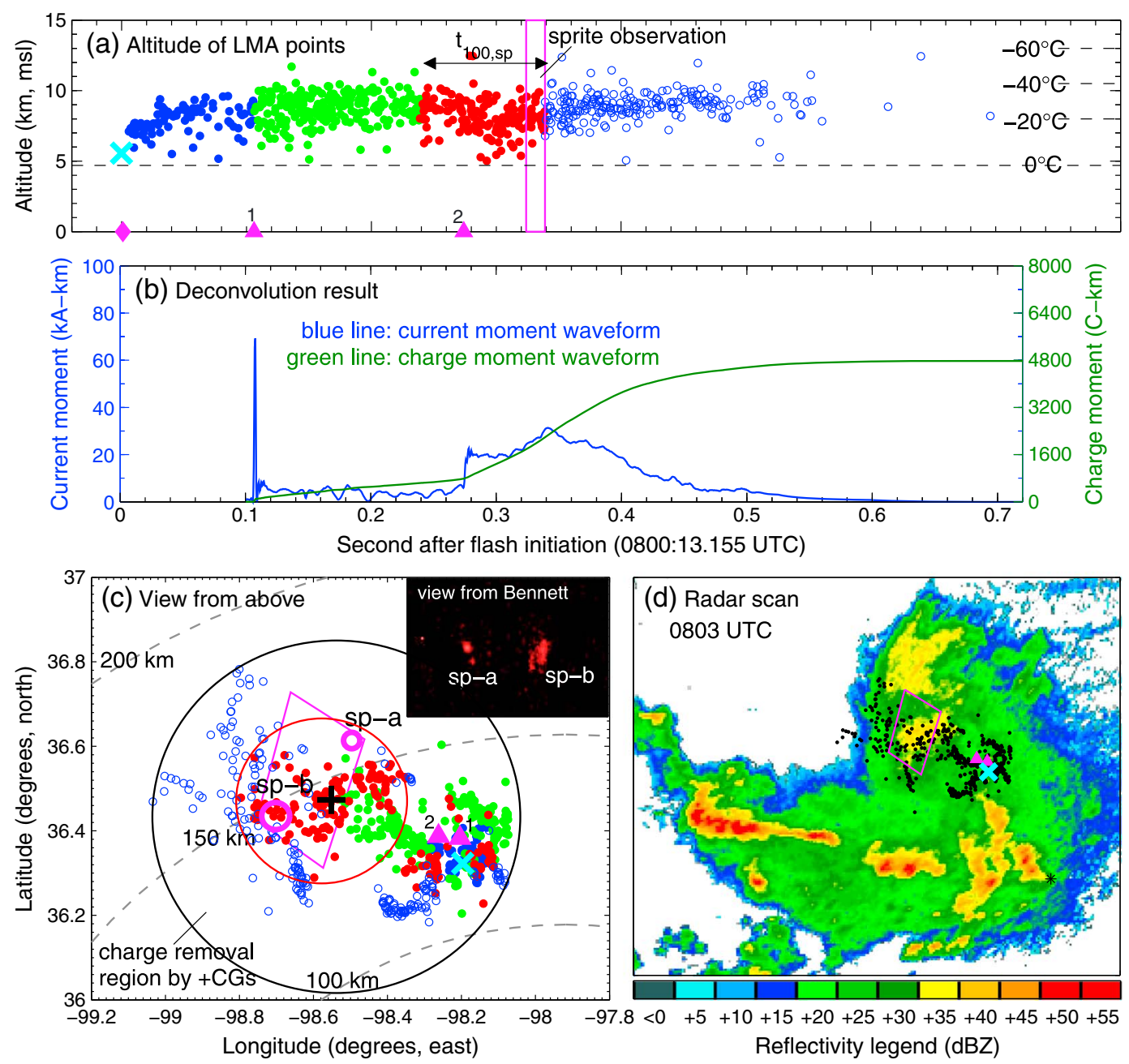

Figure 10. Coordinated observation of a delayed sprite at 0800 UTC with two elements that were both laterally offset from the causative stroke by $>30 \mathrm{~km}$. (a) Time-altitude plot of LMA sources after the flash initiated at $6 \mathrm{~km}$ MSL altitude. (b) Time-resolved current moment and charge moment for the SP+CG stroke. (c) Plan view of flash structure in comparison with the triangulated location (pink circles) of two sprite elements (denoted as sp-a and sp-b). (d) Comparison between flash structure, sprite production, and radar scan from Dodge City, Kansas, showing that the sprite-parent flash initiated in the stratiform region.

None of these current surges was caused by new ground strokes, leaving a most probable connection with $M$ components [Rakov et al., 2001; Yashunin et al., 2007; Asano et al., 2009a]. As shown in Figure 11c, the progression of negative leaders branched extensively in the stratiform; individual sprite elements appeared as "fruits" on the branches rooted in the flash initiation region. All of these sprites were delayed events, and none of them was particularly bright. Interestingly, although negative leaders in this flash also propagated over the secondary maximum of radar reflectivity ( $\geq 35 \mathrm{dBZ}$ ) in the stratiform, all the sprite elements were produced above the edge of enhanced reflectivity.

[59] This is another stratiform-initiated sprite-parent flash that primarily developed at the temperate level of $-20^{\circ} \mathrm{C}$. The NLDN reported two + CG strokes and four + IC events for the flash. The first $+\mathrm{CG}$ occurred $0.2 \mathrm{~s}$ after flash onset, not far from the flash origin, and produced an iCMC of $+124 \mathrm{C} \mathrm{km}$. The ensuing continuing current remained at a level of $>1 \mathrm{kA}$ for more than $500 \mathrm{~ms}$, reaching peak magnitude of $>5 \mathrm{kA}$ and leading to a total charge moment change of $+13,000 \mathrm{C} \mathrm{km}$. There was no sprite observation after the continuing current began to decay gradually toward the end of the flash, even at the time of a second +CG with an iCMC of $+140 \mathrm{C} \mathrm{km}$. Instead of identifying LMA sources within $100 \mathrm{~ms}$ before each sprite element, we outline the cloud region of positive charge removal responsible for sprites with the LMA sources detected from $100 \mathrm{~ms}$ before the first sprite element until the last sprite element (denoted as $t_{\mathrm{sp}}$ in Figure 11a). The geometric center (black plus in Figure 11c) of these LMA sources is located at $8.1 \mathrm{~km}$ MSL $\left(-18^{\circ} \mathrm{C}\right)$ or $7.7 \mathrm{~km}$ above ground level. Therefore, + CG strokes in this flash removed near $1700 \mathrm{C}$ positive charge from the trailing stratiform. For this flash, we constrain the positive charge removal with a $2 \mathrm{~km}$ deep circular region roughly encompassing the entire flash, and the average density of positive charge depletion is $0.103 \mathrm{nC} / \mathrm{m}^{3}$.

[60] A further examination of individual sprite elements indicates that the time-resolved spatial structure of sprite 

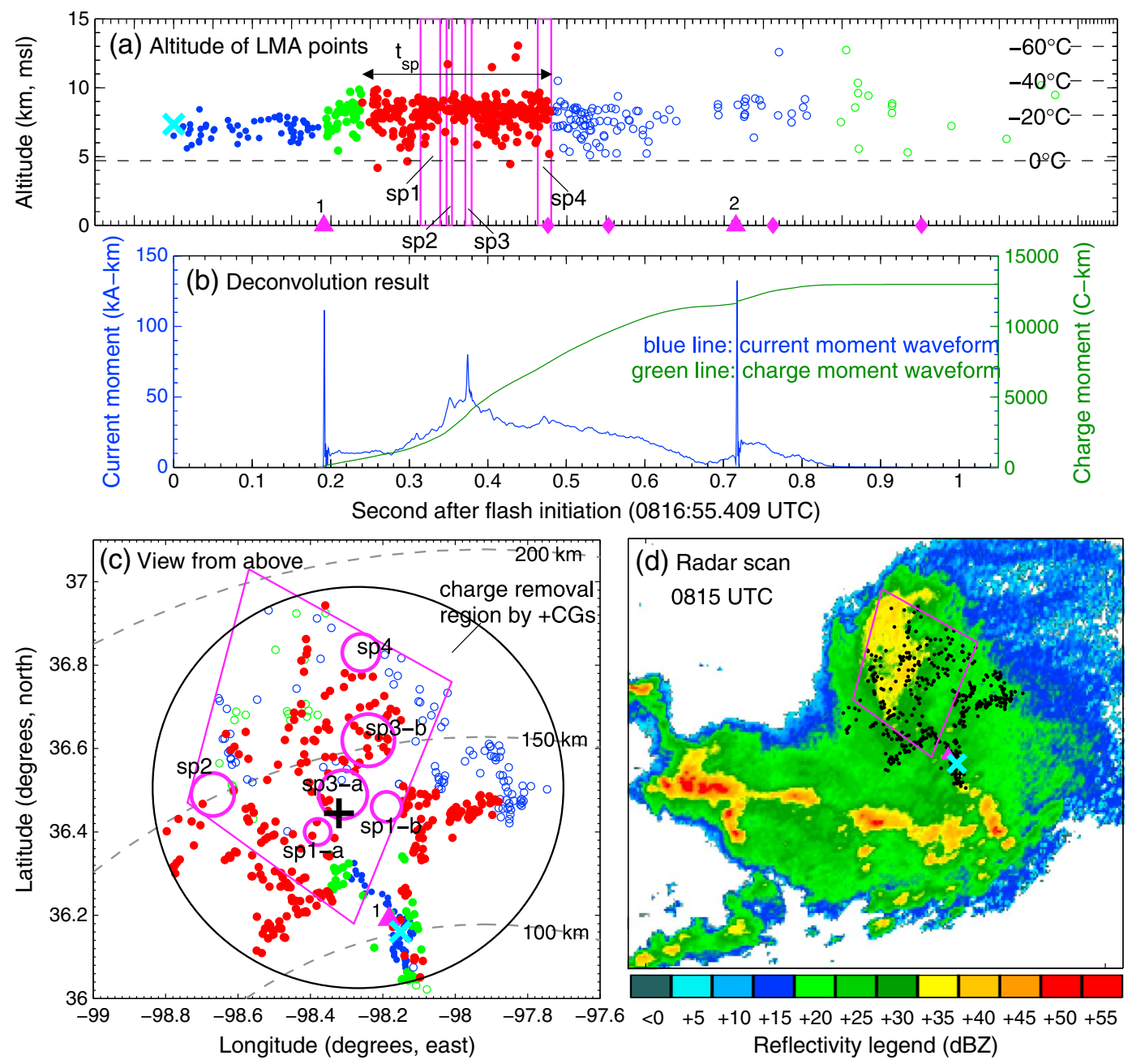

Figure 11. Coordinated observation of a sequence of six sprite elements (as a dancing event) at 0816 UTC that were produced through intermittent current surges during a long continuing current. (a) Time-altitude plot of LMA sources after the flash initiated near $7 \mathrm{~km}$ MSL altitude in the stratiform. (b) Time-resolved current moment and charge moment for the SP+CG stroke. (c) Plan view of flash development with extensive branching in the trailing-stratiform region (shown by LMA sources during the $t_{\mathrm{sp}}$ interval) during the sprite production interval. The triangulated positions of individual sprite elements are indicated by pink circles. (d) Comparison between flash structure, triangulated sprite production, and radar scan from Dodge City, Kansas, showing that the sprite-parent flash also initiated in the stratiform region.

generally reflects the progression of negative leaders through the positively charged region in the stratiform. In Figure 12, columns a and c show the image of sprite elements observed from two cameras; column $\mathrm{b}$ shows the lightning progression with LMA sources within $100 \mathrm{~ms}$ (red dots in each panel) before each element (or since the previous element), and the plus symbol marks the geometric center of these LMA sources. In general, the sprite element was produced above the active negative leader progression in the prior tens of milliseconds, which is most distinct for the last element (sp4) that was relatively separated in time from prior elements. On the other hand, not all the negative leader progression lead to an observable sprite, which suggests that the current surges responsible for triggering sprite might be linked to localized positive charge concentration in the stratiform. LMA observations coordinated with high-speed sprite imaging are desired to reveal more details regarding the correlation between sprite dynamics and in-cloud negative leader progression.

\section{3. +CG at 1005:54.528 UTC}

[61] For the last case study, we examine a complex flash (Event 26 in Table 1) near the end of the observation on 29 June that produced two sprites as a simple dancing event through distinct strokes. The main discussion regards the first sprite as a delayed event. A total of five $+\mathrm{CG}$ strokes were reported by the NLDN for this flash, all with peak currents in excess of $30 \mathrm{kA}$, and another $25 \mathrm{IC}$ events were detected. The flash initiated near the leading convection (Figure 13d) and developed two major extensions (shown by LMA sources marked as green and blue dots, respectively) that generally progressed eastward and northward, 
(a) View from Bennett
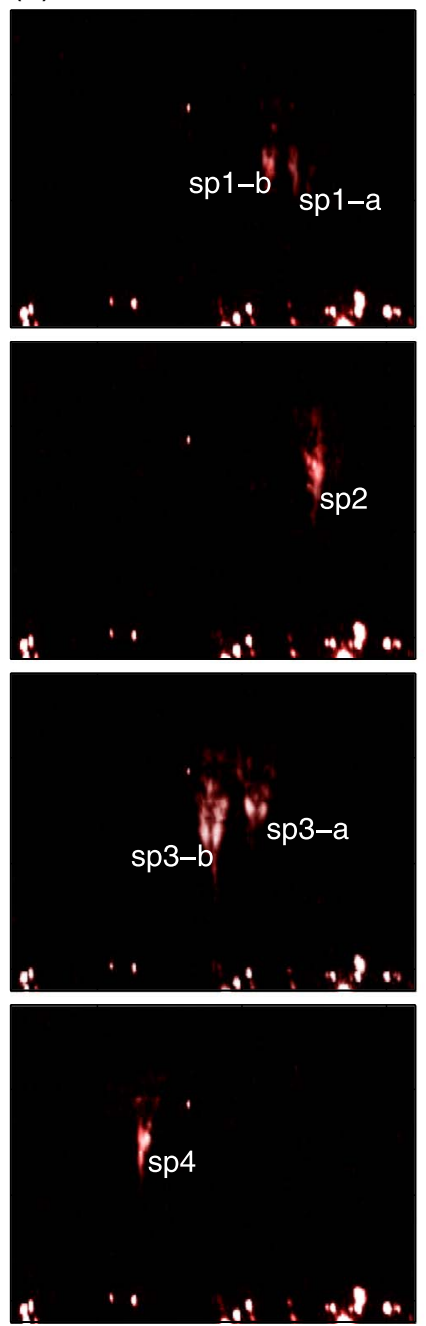

(b) Oklahoma LMA
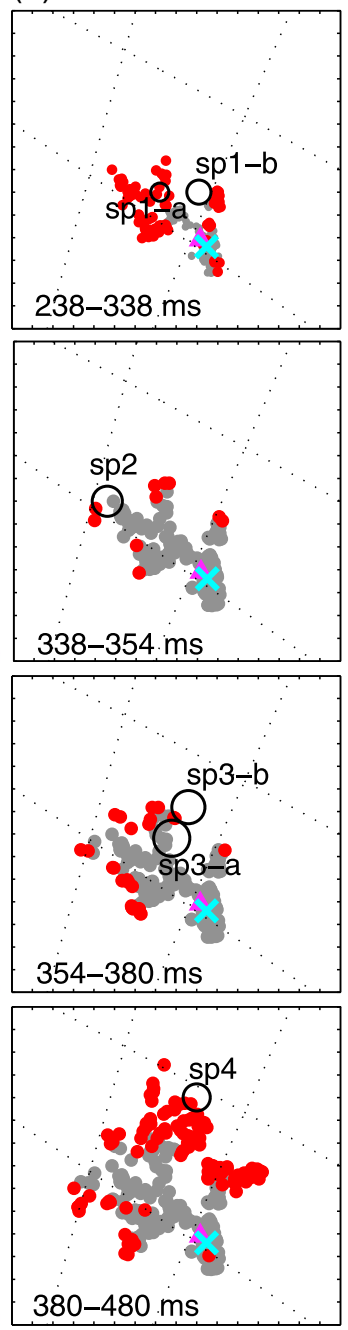

(c) View from Hawley
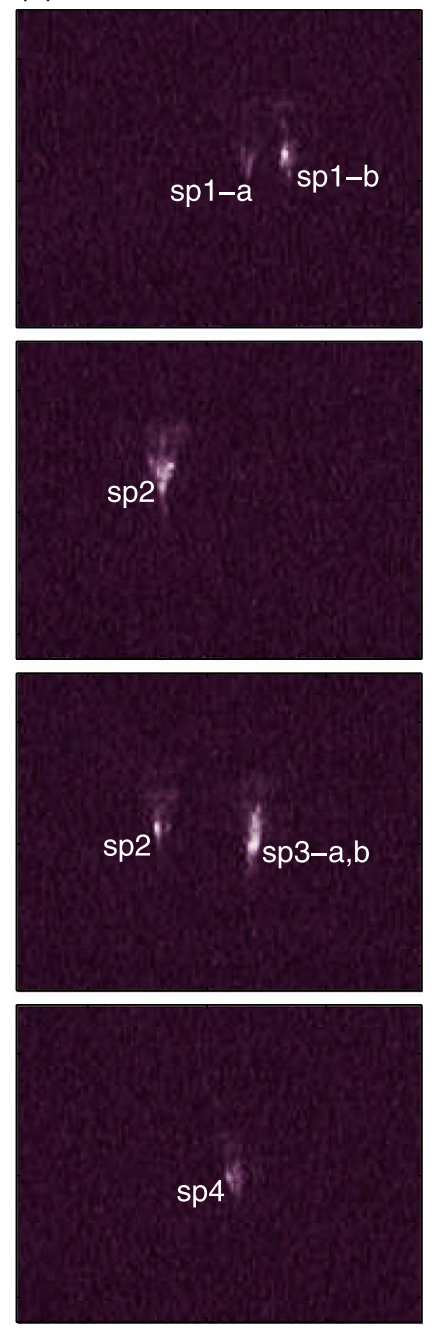

Figure 12. Temporal development of a series of sprite elements (as a "dancing/jumping" event), as observed from Bennett (column a) and Hawley (column c) at 0816 UTC, in comparison with the flash development shown by the OKLMA (column b). In column b, red dots show LMA sources during the specified time interval after the flash initiation (cyan cross), and gray dots show previous LMA sources. In general, the variation in the location of sprite elements reflects the progression of multiple negative leaders during the continuing current initiated by the $\mathrm{SP}+\mathrm{CG}$ stroke (pink triangle).

respectively (Figure 13c). The negative leaders in both directions propagated in positively charged cloud regions centered above the freezing level.

[62] The first sprite produced in this flash consisted of $\geq 5$ vertically aligned elements that all appeared between $44 \mathrm{~ms}$ and $55 \mathrm{~ms}$ after the first stroke with an iCMC of $+157 \mathrm{C} \mathrm{km}$. This stroke initiated a continuing current of $200 \mathrm{~ms}$ and produced a total $\mathrm{CMC}$ of $+4000 \mathrm{C} \mathrm{km}$. The sprite was produced with short delay (4-15 ms) after a second $+C G$ that gave rise to a current surge superposed on the continuing current; here we did not identify the second stroke, with an iCMC of $+60 \mathrm{C} \mathrm{km}$, as the causative stroke because its role is essentially the same as the $M$ component associated with other delayed sprites. Note that the first $+\mathrm{CG}$, which is designated as the causative stroke, appeared to originate from the lightning channel that propagated northward. The associated sprite, however, was produced above the eastward channel extension that dominated the charge transfer linked to the continuing current. Therefore, it seems the two major extensions of the flash remained electrically connected $700 \mathrm{~ms}$ after the flash onset, and the negative breakdown launched by the first $+\mathrm{CG}$ was able to propagate over the full extent of in-cloud negative channels. A burst of 15 negative IC events occurred after the first sprite (Figure 13a), most of which likely reflect a downward migration (to lower altitudes of the stratiform) of negative charge deposited by the continuing current. Again, a few such negative ICs were classified by the NLDN as negative CGs with peak currents higher than $30 \mathrm{kA}$.

[63] The third stroke, with a large iCMC of $+992 \mathrm{C} \mathrm{km}$, produced a prompt, bright sprite embedded in a distinct halo with small offset $(<10 \mathrm{~km})$ from the ground stroke. This sprite-halo event was clearly above negative leader progression (red circles) immediately prior to the sprite (Figures 13a 

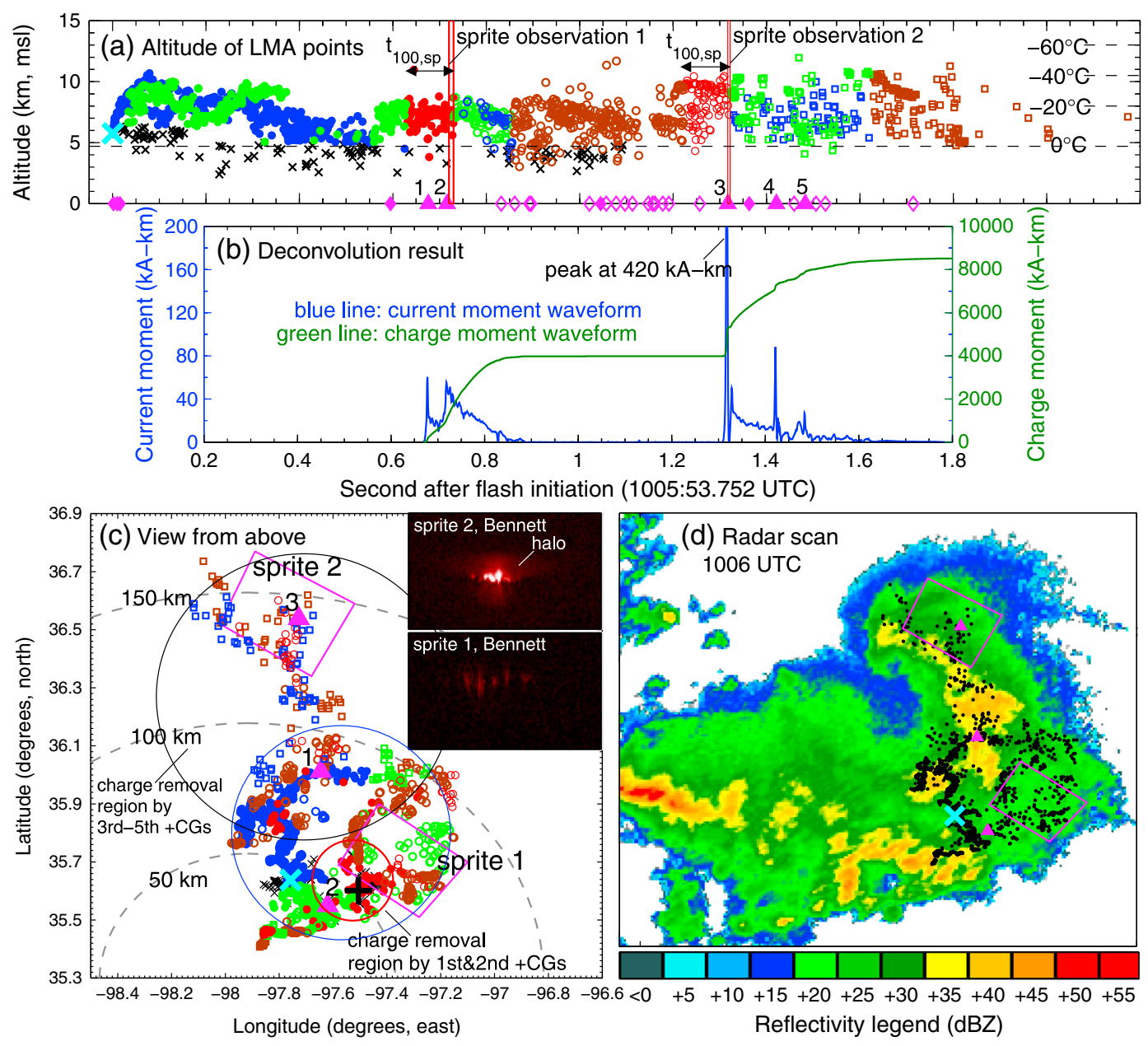

Figure 13. Coordinated observation of two sprites at 1005 UTC that were produced by two distinct $+\mathrm{CG}$ strokes in the same flash. (a) Time-altitude plot of LMA sources after the flash initiated at $6 \mathrm{~km}$ MSL altitude in the convection region. (b) Time-resolved current moment and charge moment for SP+CG strokes. (c) Plan view of flash development with two major extensions that progressed eastward and northward, respectively. (d) Comparison between flash structure, triangulated sprite production, and radar scan from Dodge City, Kansas, showing that two sprites were produced over well-separated regions of the stratiform.

and $13 \mathrm{c}$ ). During the subsequent continuing current of $240 \mathrm{~ms}$, another two +CGs occurred without leading to further discernible optical emission, and the total charge moment change of the entire flash accumulated to $+8510 \mathrm{C} \mathrm{km}$.

[64] In summary, both sprites in this flash were produced above two regions separated by near $100 \mathrm{~km}$ in the stratiform, which were both explored by negative leaders within $100 \mathrm{~ms}$ before the sprite. For the delayed sprite, the center of formation is displaced from the parent stroke by $44 \mathrm{~km}$, whereas it is only $27 \mathrm{~km}$ from the geometric center (at $7.0 \mathrm{~km} \mathrm{MSL},-17^{\circ} \mathrm{C}$ ) of clustered LMA sources (in the red circle) under the region of sprite production. We estimated the average positive charge removal density by the first stroke from the cloud region (a blue circle in Figure 13c) that encloses LMA sources during the subsequent continuing current. For this circular region centered at $6.6 \mathrm{~km}$ AGL, the estimated positive charge removal by the first two strokes is $0.078 \mathrm{nC} / \mathrm{m}^{3}$; the same method applied to the charge transfer of the last three $+\mathrm{CG}$ strokes estimates the average charge removal density to be $0.045 \mathrm{nC} / \mathrm{m}^{3}$.
[65] On 29 June, a total of 14 "dancing" sprites were observed with at least two sprites showing distinct separation in space and time. Three of them, including the long sprite sequence examined in section 5.2, were produced (all as delayed events) through current surges superposed on an intense continuing current (on $\sim 20 \mathrm{kA} \mathrm{km} \mathrm{level} \mathrm{for} \mathrm{a}$ substantial duration). In another three cases, the impulse charge transfer of the leading stroke and subsequent current surges during continuing current produced prompt and delayed sprites, respectively. The remaining eight "dancing" sprites were all produced through discrete $+\mathrm{CG}$ strokes in the same flash that were separated by $200-700 \mathrm{~ms}$ in time and $35-70 \mathrm{~km}$ in ground location.

\section{Spatial Sprite-Lightning Relationship}

[66] In this section, we quantify and summarize the spatial relationship between sprites and parent lightning, using ground stroke locations and LMA-resolved in-cloud lightning activity, respectively. The $29 \mathrm{SP}+\mathrm{CG}$ strokes in Table 1 

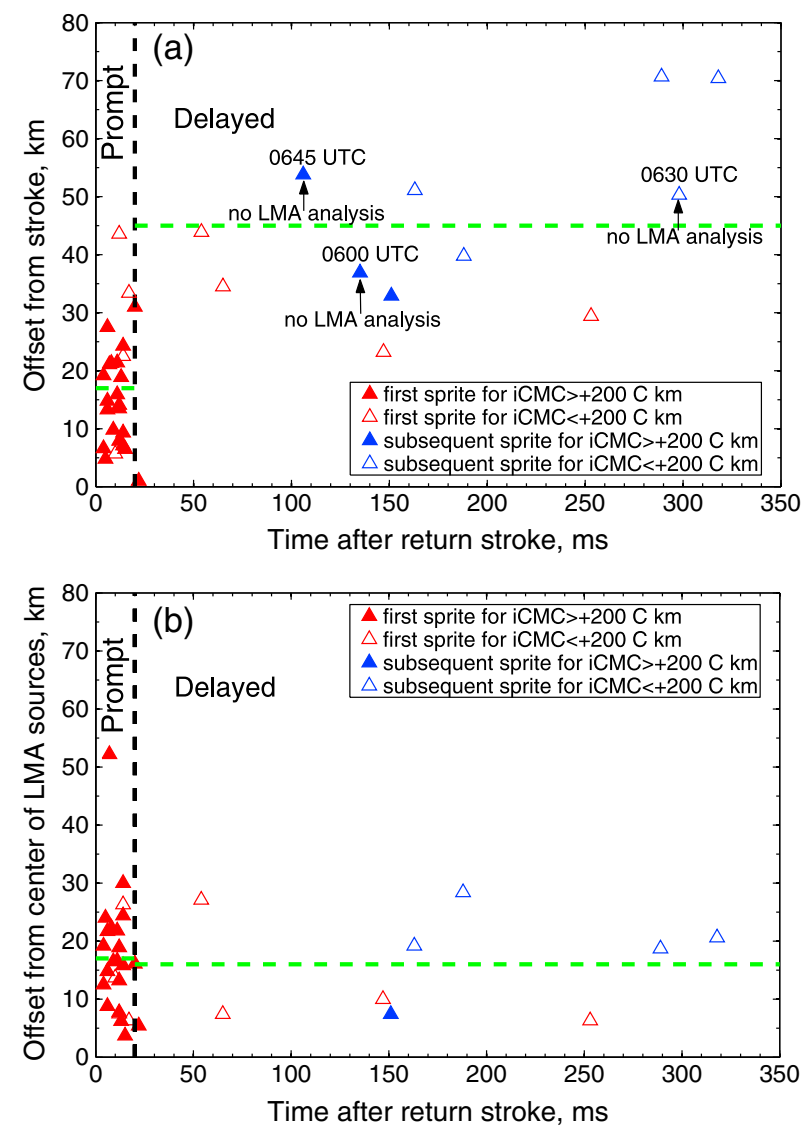

Figure 14. (a) Correlation between sprite-lightning offset (using the ground location of SP+CG strokes) and the temporal delay of sprites relative to the initial ground contact of strokes. Temporally distinguishable sprite elements produced by the SP $+\mathrm{CG}$ strokes are examined. (b) Correlation between spritelightning offset (based on LMA sources during $t_{100, \mathrm{sp}}$ ) and the delay of sprites relative to parent strokes. For three flashes before 0646 UTC (indicated by arrows in Figure 14a), the LMA data are not appropriate for analyzing the subsequent sprite. The green dashed lines in the figures show the average horizontal offset of the center of sprite production relative to the ground stroke (Figure 14a) and relative to the geometric center of selected LMA sources (Figure 14b).

are analyzed, and individual sprites at varying times after the same stroke are examined as first and subsequent sprites. We also divided strokes into two groups with iCMCs above and below $+200 \mathrm{C} \mathrm{km}$ (the nominal critical iCMC for prompt sprite production on 29 June), respectively, to explore the dependence of the spatial sprite-lightning relationship on the magnitude of impulse charge moment change.

\subsection{Spatial Offset Between Sprites and Parent Strokes}

[67] The offset between sprites and causative strokes is evaluated with the distance between the ground stroke location and the center of triangulated sprite formation $\left(D_{s-s p}\right)$, which is $26 \mathrm{~km}$ on average for triangulated sprites in our analysis. Figure 14a shows the relationship between $D_{s-s p}$ and the temporal delay of sprites after the parent stroke. Our results are generally consistent with previous observations that sprites are typically produced within $50 \mathrm{~km}$ of the causative stroke [Lyons,
1996; Wescott et al., 2001; Soula et al., 2010]. However, our results also reveal the presence of two distinct groups that reflect a dependence of sprite-stroke offset on the temporal delay of sprite production relative to the stroke:

[68] 1. Prompt sprites produced by strokes with iCMCs $+200 \mathrm{C} \mathrm{km}$ are typically centered within $30 \mathrm{~km}$ of the parent stroke. Half of the SP+CG strokes with iCMCs $<+200 \mathrm{C} \mathrm{km}$ also produced prompt sprites that exhibit a larger variance $(5$ to $45 \mathrm{~km}$ ) in the horizontal displacement from parent strokes. On average, the center of production for 25 prompt sprites is offset from the parent stroke by $17 \mathrm{~km}$.

[69] 2. Delayed sprites are typically displaced by $>30 \mathrm{~km}$ (45 km on average) from the parent stroke, regardless of iCMCs. In particular, four $+\mathrm{CG}$ strokes producing prompt sprites, three with iCMCs $>+200 \mathrm{C} \mathrm{km}$ and one with iCMC $+200 \mathrm{C} \mathrm{km}$, also produced delayed (subsequent) sprites with $>30 \mathrm{~km}$ offset from parent strokes.

[70] In contrast to our observations in Figure 14a, Füllekrug et al. [2001] and São Sabbas et al. [2003] found that a substantial fraction $(\sim 30 \%)$ of delayed sprites were minimally displaced $(<20 \mathrm{~km})$ from the ground stroke. In addition, the analyses of São Sabbas et al. [2003] show a significant population of prompt sprites with $>50 \mathrm{~km}$ lateral offset from causative strokes. The nature of lightning-sprite offset probably depends at least in part on the thunderstorm charge structure itself, and more triangulated sprite observations are anticipated to generate a robust statistical relationship between sprites and parent strokes. In particular, it is necessary to verify whether delayed sprites are usually characterized by a substantial horizontal displacement from the causative stroke.

\subsection{Relationship Between Sprite and In-Cloud Leader Activity}

[71] Here we investigate the spatial sprite-lightning relationship with in-cloud lightning activity shown by LMA sources. LMA sources during the $t_{100, \text { sp }}$ interval are used to identify the lightning activity with immediate contribution to the sprite initiation. For three $\mathrm{SP}+\mathrm{CG}$ strokes before 0646 UTC, there were no LMA sources during $t_{100, \text {,sp }}$ to examine the lightning activity linked to the subsequent sprite. Figure $14 \mathrm{~b}$ shows the offset between the geometric center of selected LMA sources and the center of sprite formation for SP+CG strokes with good LMA data. It is clear that the lateral offset, for both prompt and delayed sprites, is less than $30 \mathrm{~km}$ in all cases but one; the average offset for prompt and delayed sprites is $17 \mathrm{~km}$ and $16 \mathrm{~km}$, respectively. Consequently, the in-cloud negative leader activity resolved by the LMA sources immediately prior to sprites is generally a better indicator of sprite location than the ground stroke.

[72] Figure 15 shows the spatial relationship between sprites and preceding in-cloud lightning activity for three prompt sprites whose center of formation was laterally displaced by $>30 \mathrm{~km}$ from the causative stroke, which in two cases (Figures 15a and 15c) was under the cloud region where the flash initiated. LMA sources during $t_{100, \mathrm{sp}}$ indicate that negative leaders might extend into different regions of the cloud prior to sprites. Our analyses outline the positive charge removal involved in sprite production with the clustered LMA sources (enclosed in a red circle) in the stratiform region under the sprite. As we can see for all of these cases, negative leaders have propagated into the underneath cloud region upon the sprite initiation. The geometric center (black 

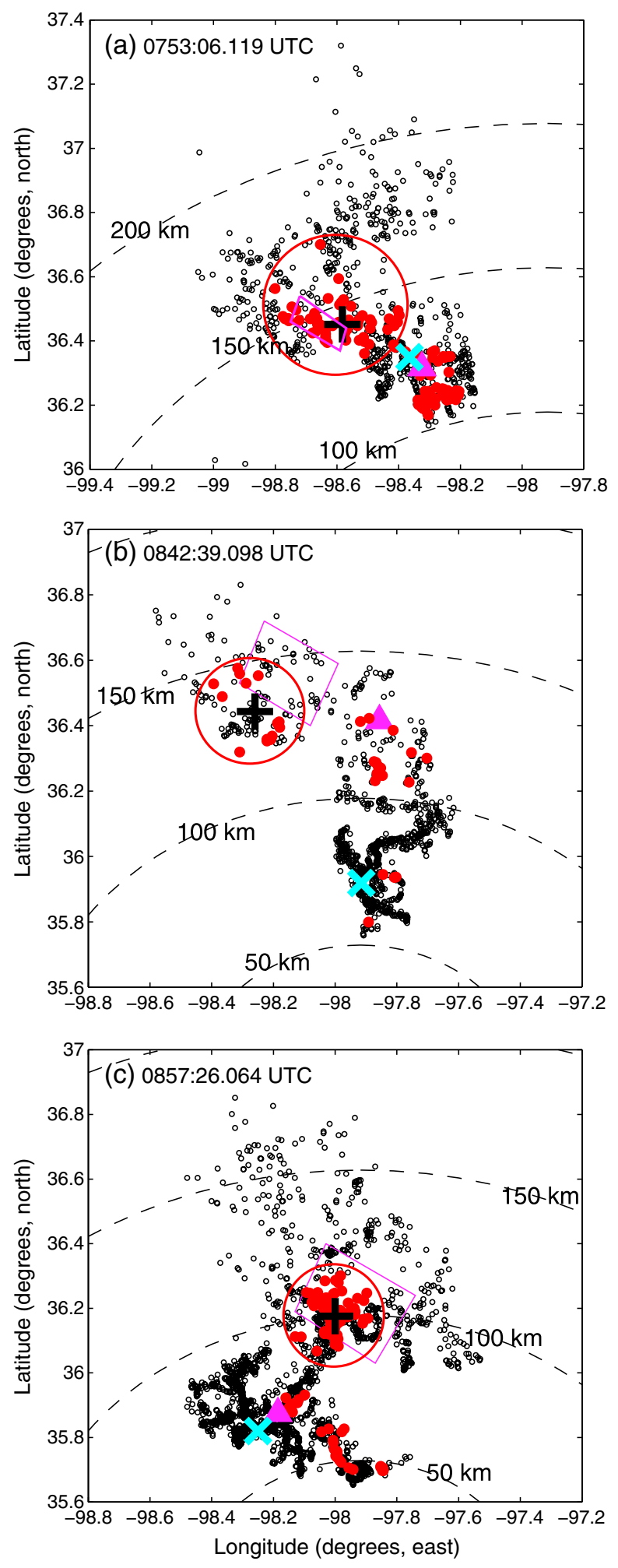

Figure 15. Spatial relationship between triangulated sprite formation (constrained in the pink rectangular region), SP + CG strokes (pink triangles), and LMA sources during $t_{100, \text { sp }}$ (red dots in the red circle, with the geometric center located at black plus) with major contribution to the sprite production, for three selected sprites whose center of formation was laterally displaced by $>30 \mathrm{~km}$ from the parent ground stroke. Other LMA sources in the flash are shown as black circles, and the flash initiation is indicated by a cyan cross. plus) of selected LMA sources is usually within $15 \mathrm{~km}$ of the center of sprite formation. In all of these cases, the center of positive charge removal is laterally displaced by $>20 \mathrm{~km}$ from the stroke, in the forward direction of negative leader progression in the stratiform.

[73] There is one exception in Figure 14b showing that the center of sprite production (for the second stroke of Flash 19 in Table 1) was substantially displaced $(>50 \mathrm{~km})$ from the primary negative leader progression during $t_{100, \mathrm{sp}}$. Figure 16 shows the analysis of this prompt sprite associated with an iCMC of $+714 \mathrm{C} \mathrm{km}$. The SP+CG stroke was laterally offset by $20 \mathrm{~km}$ from the center of triangulated sprite production (Figure 16a), which was above the secondary maximum of radar reflectivity $(\geq 35 \mathrm{dBZ})$ in the trailing stratiform (Figure 16b). Although there were some LMA sources during $t_{100, \text { sp }}$ below the sprite, the main cluster in this interval (enclosed by a red circle) was $>30 \mathrm{~km}$ from the ground stroke, with significant offset from the sprite production. Therefore, in this specific case, as well as other SP+CG strokes with iCMCs $>+200 \mathrm{Ckm}$ produced by the MCS on 29 June, the stroke location is a good indicator of prompt sprite location.

[74] In summary, our analyses suggest that the negative leader progression resolved by LMA sources within $100 \mathrm{~ms}$ prior to sprites outlines the possible region of sprite production (with uncertainty $<30 \mathrm{~km}$ for the MCS on 29 June). If we presume the sprite formation is centered above the cloud region of positive charge removal, the lateral displacement of sprites from causative strokes reflects the horizontal offset between $\mathrm{SP}+\mathrm{CG}$ strokes and the corresponding charge reservoir. Many sprites are centered roughly above the leading edge of negative leader progression upon the stroke occurrence [e.g., Stanley, 2000], indicating that more positive charge is removed from there. Electric field measurements from ground-based or airborne platforms are desirable for further sprite-LMA observations in order to fully understand the spatial relationship between sprite production, in-cloud lightning structure, and ground stroke as the sink of cloud-to-ground charge transfer.

\section{Positive Charge Reservoir for Sprites on 29 June}

[75] In this section, we discuss the positive charge reservoir with major contributions to the sprite production on 29 June. Analyses of coordinated sprite-lightning observations indicate that, in all cases but one, the center of sprite production was located within $30 \mathrm{~km}$ of the geometric center of LMA sources within $100 \mathrm{~ms}$ prior to sprites, which suggests that LMA sources during $t_{100, \text { sp }}$ can be used to constrain the in-cloud region of positive charge removal responsible for sprites. Based on this spatial relationship between sprite and in-cloud lightning activity, we examined 13 more $\mathrm{SP}+\mathrm{CG}$ strokes (produced in 13 flashes) with associated sprites recorded only by one camera. Although a triangulation of sprite location is not feasible for these strokes, they remain a valuable dataset with good LMA mapping data. The following procedures are implemented to constrain the positively charged cloud region contributing to the sprite production:

[76] 1. Identify the LMA sources during the $t_{100, \text { sp }}$ interval. The video observation from one camera is often 

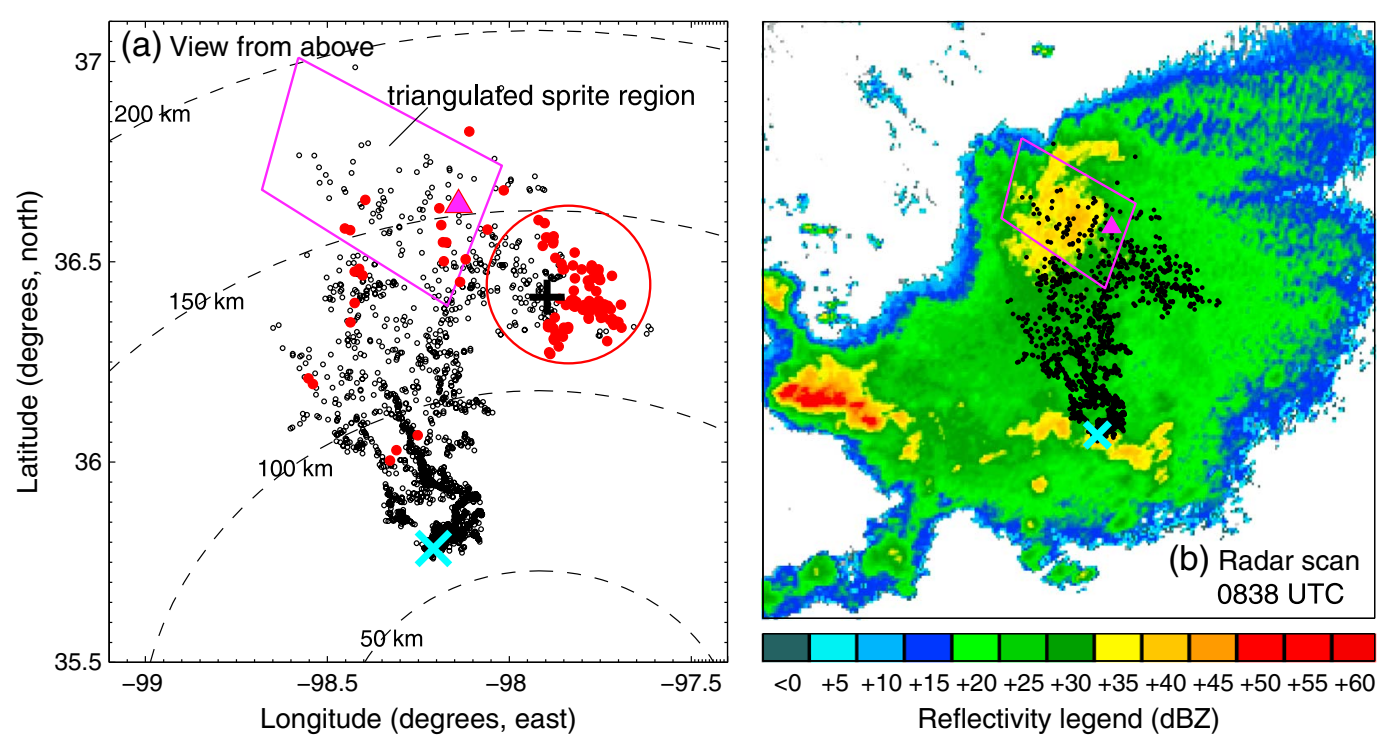

Figure 16. Lightning mapping observation of a prompt sprite produced by a $+\mathrm{CG}$ stroke at 0836:12.465 UTC on June 29 (the second SP + CG stroke of Flash 19 in Table 1). (a) Both the triangulated sprite and the $\mathrm{SP}+\mathrm{CG}$ stroke (pink triangle) were laterally displaced by $>30 \mathrm{~km}$ from the main negative leader progression (indicated by LMA sources shown as red dots enclosed by a red circle, with the geometric center located at plus) during $t_{100, \text { sp }}$ (b) Comparison with the NEXRAD radar scan from Dodge City, Kansas, shows that the flash initiation (cyan cross) was in the leading convection, and the sprite was produced over the secondary maximum of radar reflectivity ( $\geq 35 \mathrm{dBZ}$ ) in the stratiform.

sufficient to estimate a latest time of sprite initiation and thus to determine whether the sprite event is prompt or delayed.

[77] 2. Identify the major lightning progression related to the sprite formation by visually looking for clustered LMA sources. For prompt sprites, we look for the clustered LMA sources near the stroke location during $t_{100, s p}$; for delayed sprites, we identify the most significant cluster of LMA sources without regarding the stroke location.

\subsection{Altitude of Positive Charge Region Involved in Sprite Production}

[78] We computed the original altitude of positive charge removal $\left(H_{+\mathrm{SP}}\right)$ linked to sprite production with the average altitude of LMA sources identified with these procedures. The results are plotted in Figure 17 along with that for triangulated sprites, showing $H_{+\mathrm{SP}}$ for sprite-parent flashes at different times into the MCS. The time history of $H_{+\mathrm{SP}}$ for a total of $42 \mathrm{SP}+\mathrm{CG}$ strokes over approximately $4 \mathrm{~h}$ confirm that even in the same storm, the altitude of positive charge region tapped by $+\mathrm{CG}$ strokes may vary significantly as the storm evolves [Lu et al., 2009; Lang et al., 2010]. Moreover, our results indicate a specific pattern of this variation: as the MCS evolved through the mature stage with an expanding stratiform region, the altitude of positive charge layer involved in the sprite production gradually dropped from around $10 \mathrm{~km} \mathrm{MSL}\left(-35^{\circ} \mathrm{C}\right)$ to near $6 \mathrm{~km} \mathrm{MSL}$ $\left(-10^{\circ} \mathrm{C}\right)$ [Ely et al., 2008]. In general, the positive charge removed by $\mathrm{SP}+\mathrm{CG}$ strokes was originally located between $5.0 \mathrm{~km}$ and $11.0 \mathrm{~km}$ MSL (in the temperature range of $-5^{\circ} \mathrm{C}$ to $-45^{\circ} \mathrm{C}$ ). On average, the positive cloud region tapped by $\mathrm{SP}+\mathrm{CG}$ is centered at $3.6 \mathrm{~km}$ above the freezing level or at $7.9 \mathrm{~km}$ above ground level.

[79] According to the conceptual charge structure of MCSs based on balloon soundings [Stolzenburg et al., 1998], in the trailing stratiform there are two positive charge layers centered at the temperature levels of $0^{\circ} \mathrm{C}$ and $-25^{\circ} \mathrm{C}$, respectively. Our analyses of $42 \mathrm{SP}+\mathrm{CG}$ strokes generated by the MCS on 29 June indicate that the upper positive layer is the major charge reservoir for sprites, in agreement with previous studies [Lang et al., 2010], and similar to wintertime MCS-like spriteproducing storms in Japan [Suzuki et al., 2006, 2011]. The upper positive charge layer could also be directly involved in sprite-parent flashes that initiate in the stratiform, which has been reported by Lang et al. [2010] and was also observed for three sprite-producing flashes on 29 June.

[80] The assertion that the upper positive charge layer in the trailing stratiform of MCSs is the major source for $\mathrm{SP}+\mathrm{CG}$ strokes, however, does not exclude the lower

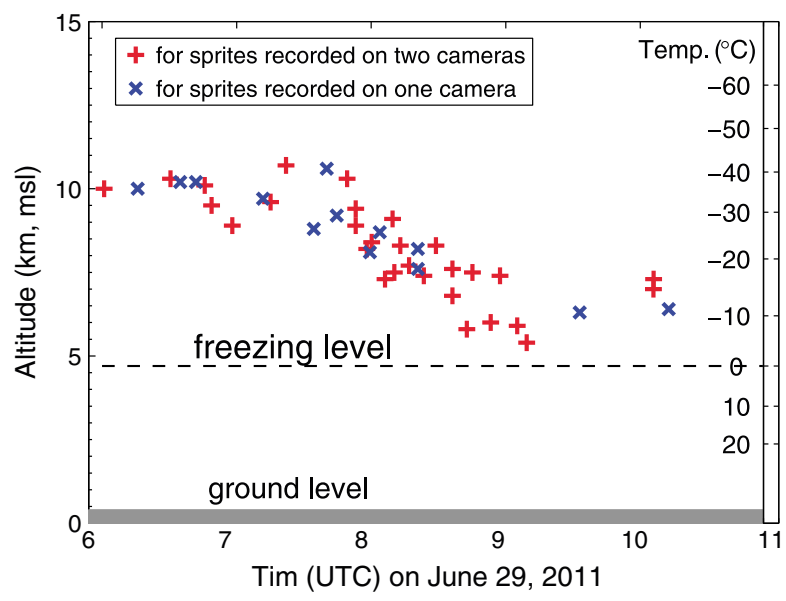

Figure 17. Estimated original altitude of positive charge transferred to the ground by $42 \mathrm{SP}+\mathrm{CG}$ strokes produced by the MCS on 29 June 2011. 
positive layer from being involved in flash development. The downward progression of negative leaders after the continuing current might extend into the lower positive region, leading to extensive lightning channels spreading near the cloud base. It is not clear whether such lightning progression is linked to the so-called "spider lightning" crawling near the bottom of the stratiform [Mazur et al., 1998], and video observations of spider lightning with simultaneous LMA and broadband sferic measurements are desirable to elucidate the relationship between spider lightning and continuing current in $+\mathrm{CG}$ strokes. This is important because spider lightning has been quoted as evidence that the lower positive region near the freezing level in the MCS stratiform is the main charge reservoir of $\mathrm{SP}+\mathrm{CG}$ strokes, presumably due to its predominance (in terms of charge density) relative to the upper positive layer [Williams, 1998]. There are analyses, also based on coordinated sprite-lightning observations near the LMA, indicating that the charge source of $\mathrm{SP}+\mathrm{CG}$ strokes could be located below the freezing level [Lyons et al., 2003, Table 1]. However, all but one of these analyses were based on LMA sources at $>100 \mathrm{~km}$ range from the LMA origin, and the results are subject to a relatively large uncertainty; for the remaining one case with LMA sources at $\sim 50 \mathrm{~km}$ range, our method estimates the altitude of positive charge removal to be around the freezing level, instead of $0.5 \mathrm{~km}$ below as estimated by Lyons et al. [2003]. Therefore, to our best knowledge, there is no convincing evidence showing that the original altitude of positive charge removed by $\mathrm{SP}+\mathrm{CG}$ could be lower than the freezing level (at least in the majority cases). On the other hand, it is possible that the upper positive charge layer and hence the propagation of intrusive negative leaders might extend to lower altitudes below the freezing level at some parts in the stratiform, as implied by the variation in the altitude of negative leader progression in the stratiform [Carey et al., 2005]. The spreading of negative leaders (especially those from the leading convection) in the stratiform often induces negative IC events (usually after the continuing current). Some of these negative ICs would be classified by the NLDN as negative CG strokes and might affect to some extent the statistical analyses of lightning genesis associated with mesoscale convective systems. However, the propagation of highly charged negative leaders at relatively low altitudes in the stratiform does substantially enhance the chance of triggering upward positive leaders from elevated objects on ground and resulting in negative strokes [Warner et al., 2012]. For example, Soula et al. [2010] reported occurrence of negative CGs late in sprite-parent flashes in a Mediterranean winter storm with the freezing level at about $1 \mathrm{~km}$ MSL.

\subsection{Average Charge Removal Density by SP+CG Strokes}

[81] To calculate the average charge removal density of $\mathrm{SP}+\mathrm{CG}$ strokes, we assumed a depth of $2 \mathrm{~km}$ for the positive charge layer, as shown in the conceptual charge structure of MCSs [Stolzenburg et al., 1998]. As shown in Figure 17, the estimated altitudes of charge reservoirs for $\mathrm{SP}+\mathrm{CGs}$ exhibit a variation of about $2 \mathrm{~km}$, which might reflect the actual thickness of the positive charge layer with major contribution to sprite production over the MCS on 29 June.

[82] With our method confining the positive charge removal region by $\mathrm{SP}+\mathrm{CG}$ strokes, the estimated average charge removal density of six $\mathrm{SP}+\mathrm{CGs}$ ranges from $0.045 \mathrm{nC} / \mathrm{m}^{3}$ to $0.103 \mathrm{nC} / \mathrm{m}^{3}$. Our results are substantially smaller than the estimate (between $1.0 \mathrm{nC} / \mathrm{m}^{3}$ and $2.0 \mathrm{nC} / \mathrm{m}^{3}$ ) reported by Lang et al. [2011], who used the same method as ours to estimate the charge moment change of $+\mathrm{CG}$ strokes. The dramatic difference in estimated charge removal density is mainly because of distinct approaches to calculating the charge depletion volume. Lang et al. [2011] calculated the volume of positive charge removal by counting the number of $1 \mathrm{~km}^{3}$ cubes that contains at least one LMA source. Their estimates are generally in the broad range of positive cloud charge density $\left(0.1-2.8 \mathrm{nC} / \mathrm{m}^{3}\right)$ as interpreted from balloon soundings of electric fields through the stratiform of MCSs [Marshall and Rust, 1993; Marshall et al., 2001]. In particular, Marshall et al. [2001] analyzed a balloon sounding around the time of six high peak-current $(>32 \mathrm{kA})+\mathrm{CG}$ strokes and identified two positive charge layers (both of $400-500 \mathrm{~m}$ thickness) between 5 and $7 \mathrm{~km}$ (above the freezing level at $4.2 \mathrm{~km}$ ). The positive charge density in both of these charge layers was $2.0 \pm 0.2 \mathrm{nC} / \mathrm{m}^{3}$.

[83] Due to the lack of a sophisticated method to identify the exact cloud region drained by SP+CG strokes, we outlined the region of positive charge depletion with a $2 \mathrm{~km}$ thick circular plate that encloses LMA sources detected during the $+\mathrm{CG}$. This undoubtedly will underestimate the average density of positive charge removal by $\mathrm{SP}+\mathrm{CG}$ strokes (by overestimating the size of charge removal). Also, a $2 \mathrm{~km}$ depth might be too much for the positive charge layer explored by negative leaders in a specific flash. Therefore, our estimate of average charge removal density by $\mathrm{SP}+\mathrm{CG}$ strokes reflects more about the effect of a specific $\mathrm{SP}+\mathrm{CG}$ stroke on the entire positively charged region in the stratiform. Nevertheless, to precisely evaluate the average charge removal density by $\mathrm{SP}+\mathrm{CG}$ strokes, we need better methods to outline the three-dimensional cloud region tapped by negative lightning leaders.

\section{Summary}

[84] In this paper, we examined the coordinated spritelightning observations on 29 June 2011 over an asymmetric mesoscale convective system near the Oklahoma LMA. Broadband $(<1 \mathrm{~Hz}$ to $300 \mathrm{kHz})$ lightning sferics were recorded near Duke University and at other stations near the OKLMA. The main analysis concerns the sprites (associated with 26 parent flashes) that could be triangulated with simultaneous observations from Bennett, Colorado and Hawley, Texas. Most of these sprites were produced by $+\mathrm{CG}$ strokes that struck ground under the trailing stratiform of the MCS. The in-cloud lightning activity associated with the majority $(\sim 90 \%)$ of these sprites was resolved by the LMA with good temporal and spatial resolution, suitable for an analysis of in-cloud positive charge removal by $\mathrm{SP}+\mathrm{CG}$ strokes.

[85] Many sprite-parent flashes bear the features first identified by Stanley [2000] for sprites observed over an MCS in Florida. Most flashes initiate as ordinary bilevel intracloud (IC) lightning in the leading convection of MCSs and propagate into the trailing stratiform to culminate energetic $+\mathrm{CG}$ strokes that typically produce sprites with short delays. On the other hand, sprite-parent flashes are also observed to initiate in the trailing stratiform [e.g., Lang et al., 2010], 
and $\mathrm{SP}+\mathrm{CG}$ strokes with this morphology tend to produce sprites with relatively long delays. The main findings of our analysis are summarized as follows:

[86] 1. Analyses of triangulated sprites indicate that sprites are usually not centered above the ground stroke, even for exceptionally bright events. Our results reveal a dependence of sprite-stroke offset on the temporal delay relative to the return stroke. Prompt sprites ( $<20 \mathrm{~ms}$ after the stroke), which are typically produced by strokes with relatively large iCMCs, are usually centered within $30 \mathrm{~km}$ of the stroke. Larger offsets $(>30 \mathrm{~km})$ are often observed for delayed sprites that typically occur $>40 \mathrm{~ms}$ after the parent stroke, upon current surges (due to $M$ components or subsequent $+\mathrm{CG}$ strokes) superposed on the continuing current.

[87] 2. On the other hand, the comparison between triangulated sprites and LMA-mapped lightning activity indicates that sprites are usually centered within $30 \mathrm{~km}$ from the cloud region explored by the most recent negative leaders (for example, within $100 \mathrm{~ms}$ prior to sprite production). This is true for both prompt and delayed sprites and also for multiple sprites produced in one lightning flash through distinct strokes or intermittent current surges during the continuing current. Therefore, observations of sprites substantially displaced from causative strokes are not inconsistent with the quasi-electrostatic model of sprites [Pasko et al., 1997] except for that most models adopt a simplified geometry for the charge transfer in SP+CG strokes [e.g., Hu et al., 2007; Li et al., 2008]. In addition, the large-scale structure of sprites might be affected by the in-cloud structure of negative leader progression (or positive charge removal), which has been demonstrated theoretically by Asano et al. [2009b].

[88] 3. It is confirmed that iCMCs serve an efficient metric to evaluate the potential of sprite production. For the MCS on 29 June, once a lightning flash spawns a +CG stroke with iCMC $>+300 \mathrm{C} \mathrm{km}$, it is $90 \%$ likely to generate a sprite. Many sprites are observed over the secondary maximum of radar reflectivity $(\geq 35 \mathrm{dBZ})$ in the stratiform, implying the presence of a substantial positive charge concentration in this region.

[89] After demonstrating the spatial relationship between triangulated sprites and in-cloud lightning activity during the prior $100 \mathrm{~ms}$, we identify the positive cloud region responsible for other sprites over the same storm as only observed by one camera. The analysis of original altitude of positive charge depleted by a total of $42 \mathrm{SP}+\mathrm{CG}$ strokes indicate that positively charged cloud regions involved in sprite production descended from about $10 \mathrm{~km} \mathrm{MSL}$ (between $-40^{\circ} \mathrm{C}$ and $\left.-30^{\circ} \mathrm{C}\right)$ to near $6 \mathrm{~km}\left(-10^{\circ} \mathrm{C}\right)$ during the mature stage of the $\mathrm{MCS}$, in correspondence with an expansion of the trailing stratiform [e.g., Ely et al., 2008]. On average, the original altitude of positive charge removed by $\mathrm{SP}+\mathrm{CG}$ strokes is $3.6 \mathrm{~km}$ above the freezing level. For the MCS on 29 June, the major charge reservoir for sprites is the upper positive charge layer illustrated in the conceptual charge structure of the MCS trailing stratiform. The lower positive charge region near the freezing level, however, might be involved in the in-cloud progression of negative leaders in a certain way that remains to be investigated. Negative IC events that often occur subsequent to continuing current in $\mathrm{SP}+\mathrm{CG}$ strokes are likely linked to this process.

[90] Our results suggest that the LMA sources immediately prior to sprites can be used as a good indicator of the horizontal location of high electric field region at high altitudes where the sprite would be triggered. For the cases in our analysis, the center of sprite formation is offset by $<20 \mathrm{~km}$ on average from the geometric center of LMA sources within $100 \mathrm{~ms}$ before the sprite. In order to evaluate how the in-cloud geometry of charge transfer affects the exact region where the sprite is produced, more details about the spatial distribution of charge transfer during $\mathrm{SP}+\mathrm{CG}$ strokes remain to be revealed, for example, through ground-based or balloon-borne measurements [e.g., Lu et al., 2011] of electric fields at sufficiently close distances $(<10 \mathrm{~km})$ from in-cloud negative leader progression during the lightning charge transfer that eventually leads to sprites.

[91] Acknowledgments. We wish to dedicate this paper to the memory of contributor Tim Samaras, who tragically perished along with his son Paul Samaras and fellow severe storm researcher Carl Young during the El Reno, Oklahoma EF-5 tornado on 31 May 2013 while collecting vital in-situ measurements. This work was supported by the DARPA Nimbus program and the NSF Physical and Dynamic Meteorology program. Many people offered help to install and operate SpriteCam and LF systems, including Eric Cramer, Shahab Arabshahi, and Joseph Dwyer from Florida Institute of Technology; Thomas C. Marshall, Maribeth Stolzenburg, and Sumedhe Karunarathne from University of Mississippi; James Roberts and Krokhin Arkadii from University of North Texas; and Ruth Douglas Miller and Liang-Wu Cai from Kansas State University. Danyal Petersen provided the access to OKLMA data. The work of Gaopeng Lu on sprites was supported by William P. Winn of Langmuir Laboratory and the Matuszeski Graduate Research Fund of New Mexico Tech.

\section{References}

Adachi, T., H. Fukunishi, Y. Takahashi, and M. Sato (2004), Roles of the EMP and QE field in the generation of columniform sprites, Geophys. Res. Lett., 31, L04107, doi:10.1029/2003GL019081.

Akita, M., Y. Nakamura, S. Yoshida, T. Morimoto, T. Ushio, Z. Kawasaki, and D. Wang (2010), What occurs in K process of cloud flashes?, $J$. Geophys. Res., 115, D07106, doi:10.1029/2009JD012016.

Asano, T., T. Suzuki, Y. Hiraki, E. Mareev, M. G. Cho, and M. Hayakawa (2009a), Computer simulations on sprite initiation for realistic lightning models with higher-frequency surges, J. Geophys. Res., 114, A02310, doi:10.1029/2008JA013651.

Asano, T., T. Suzuki, M. Hayakawa, and M. G. Cho (2009b), Three-dimensional EM computer simulation on sprite initiation above a horizontal lightning discharge, J. Atmos. Sol. Terr. Phys., 71(8-9), 983-990, doi:10.1016/j.jastp.2009.04.003.

Barrington-Leigh, C. P., U. S. Inan, M. Stanley, and S. A. Cummer (1999), Sprites triggered by negative lightning discharges, Geophys. Res. Lett., 26(24), 3605-3608, doi:10.1029/1999GL010692.

Bell, T. F., S. C. Reising, and U. S. Inan (1998), Intense continuing currents following positive cloud-to-ground lightning associated with red sprites, Geophys. Res. Lett., 25(8), 1285-1288, doi:10.1029/98GL00734.

Biagi, C. J., K. L. Cummins, K. E. Kehoe, and E. P. Krider (2007), National Lightning Detection Network (NLDN) performance in southern Arizona, Texas, and Oklahoma in 2003-2004, J. Geophys. Res., 112, D05208, doi:10.1029/2006JD007341.

Boccippio, D. J., E. R. Williams, S. J. Heckman, W. A. Lyons, I. Baker, and R. Boldi (1995), Sprites, ELF transients and positive ground strokes, Science, 269, 1088-1091.

Boeck, W. L., O. H. Vaughan Jr., R. J. Blakeslee, B. Vonnegut, M. Brook, J. McKune (1995), Observations of lightning in the stratosphere, $J$. Geophys. Res., 100(D1), 1465-1475.

Braun, S. A., and R. A. Houze Jr. (1994), The transition zone and secondary maximum of radar reflectivity behind a mid-latitude squall line: Results retrieved from Doppler radar data, J. Atmos. Sci., 51, 2733-2755.

Bruning, E. C., W. D. Rust, D. R. MacGorman, M. I. Biggerstaff, and T. J. Schuur (2010), Formation of charge structures in a supercell, Mon. Weather Rev., 138, 3740-3761.

Carey, L. D., M. J. Murphy, T. L. McCormick, and N. W. S. Demetriades (2005), Lightning location relative to storm structure in a leading-line, trailing-stratiform mesoscale convective system, J. Geophys. Res., 110, D03105, doi:10.1029/2003JD004371.

Chen, A. B., et al. (2008), Global distributions and occurrence rates of transient luminous events, J. Geophys. Res., 113, A08306, doi:10.1029/2008JA013101.

Coleman, L. M., T. C. Marshall, M. Stolzenburg, T. Hamlin, P. R. Krehbiel, W. Rison, and R. J. Thomas (2003), Effects of charge and electrostatic 


\section{LU ET AL.: SPRITE TRIANGULATION NEAR OKLMA}

potential on lightning propagation, J. Geophys. Res., 108, 4298, doi:10.1029/2002JD002718.

Cummer, S. A., and M. Füllekrug (2001), Unusually intense continuing current in lightning produces delayed mesospheric breakdown, Geophys. Res. Lett., 28(3), 495-498, doi:10.1029/2000GL012214.

Cummer, S. A., and U. S. Inan (1997), Measurement of charge transfer in sprite-producing lightning using ELF radio atmospherics, Geophys. Res. Lett., 24, 1731-1734.

Cummer, S. A., and U. S. Inan (2000), Modeling ELF radio atmospheric propagation and extracting lightning currents from ELF observations, Radio Sci., 35(2), 385-394, doi:10.1029/1999RS002184.

Cummer, S. A., and W. A. Lyons (2005), Implications of lightning charge moment changes for sprite initiation, J. Geophys. Res., 110, A04304, doi:10.1029/2004JA010812.

Cummer, S. A., U. S. Inan, T. F. Bell, and C. P. Barrington-Leigh (1998), ELF radiation produced by electrical currents in sprites, Geophys. Res. Lett., 25(8), 1281-1284, doi:10.1029/98GL50937.

Cummer, S. A., H. U. Frey, S. B. Mende, R. Hsu, H. Su, A. B. Chen, H. Fukunishi, and Y. Takahashi (2006), Simultaneous radio and satellite optical measurements of high-altitude sprite current and lightning continuing current, J. Geophys. Res., 111, A10315, doi:10.1029/ 2006JA011809.

Cummins, K. L., M. J. Murphy, E. A. Bardo, W. L. Hiscox, R. B. Pyle, and A. E. Pifer (1998), A combined TOA/MDF technology upgrade of the U.S. National Lightning Detection Network, J. Geophys. Res., 103, 9035-9044.

Ebert, U., S. Nijdam, C. Li, A. Luque, T. Briels, and E. van Veldhuizen (2010), Review of recent results on streamer discharges and discussion of their relevance for sprites and lightning, J. Geophys. Res., 115, A00E43, doi:10.1029/2009JA014867.

Ely, B. L., R. E. Orville, L. D. Carey, and C. L. Hodapp (2008), Evolution of the total lightning structure in a leading-line, trailing-stratiform mesoscale convective system over Houston, Texas, J. Geophys. Res., 113, D08114, doi:10.1029/2007JD008445.

Franz, R. C., R. J. Nemzek, and J. R. Winckler (1990), Television image of a large upward electrical discharge above a thunderstorm system, Science, 249, 48-51.

Füllekrug, M., D. R. Moudry, G. Dawes, and D. D. Sentman (2001), Mesospheric sprite current triangulation, J. Geophys. Res., 106(D17), 20,189-20,194, doi:10.1029/2001JD900075.

Fuquay, D. M. (1982), Positive cloud-to-ground lightning in summer thunderstorms, J. Geophys. Res., 87(C9), 7131-7140, doi:10.1029/ JC087iC09p07131.

Gamerota, W. R., S. A. Cummer, J. Li, H. C. Stenbaek-Nielsen, R. K. Haaland, and M. G. McHarg (2011), Comparison of sprite initiation altitudes between observations and models, J. Geophys. Res., 116, A02317, doi:10.1029/2010JA016095.

Gomes, C., and V. Cooray (1998), Long impulse currents associated with positive return strokes, J. Atmos. Sol. Terr. Phys., 60, 693-699.

Greenberg, E., C. Price, Y. Yair, C. Haldoupis, O. Chanrion, and T. Neubert (2009), ELF/VLF signatures of sprite-producing lightning discharges observed during the 2005 EuroSprite Campaign, J. Atmos. Sol. Terr., Phys., 71, 1254-1266.

Hager, W. W., et al. (2012), Charge rearrangement by sprites over a north Texas mesoscale convective system, J. Geophys. Res., 117, D22101, doi:10.1029/2012JD018309.

Han, F., and S. A. Cummer (2010), Midlatitude nighttime D region ionosphere variability on hourly to monthly time scales, J. Geophys. Res., 115, A09323, doi:10.1029/2010JA015437.

Houze, R. A. J., B. F. Smull, and P. Dodge (1990), Mesoscale organization of springtime rainstorms in Oklahoma, Mon. Weather Rev., 118, 613-654.

Hu, W., S. A. Cummer, W. A. Lyons, and T. E. Nelson (2002), Lightning charge moment changes for the initiation of sprites, Geophys. Res. Lett., 29(8), 1279, doi:10.1029/2001GL014593.

Hu, W., S. A. Cummer, and W. A. Lyons (2007), Testing sprite initiation theory using lightning measurements and modeled electromagnetic fields, J. Geophys. Res., 112, D13115, doi:10.1029/2006JD007939.

Huang, E., E. Williams, R. Boldi, S. Heckman, W. Lyons, M. Taylor, T. Nelson, and C. Wong (1999), Criteria for sprites and elves based on Schumann resonance observations, J. Geophys. Res., 104(D14), 16,943-16,964, doi:10.1029/1999JD900139.

Kasemir, H. W. (1960), A contribution to the electrostatic theory of a lightning discharge, J. Geophys. Res., 65(7), 1873-1878, doi:10.1029/ JZ065i007p01873.

Krehbiel, P. R. (1981), An analysis of the electric field change produced by lightning, Ph.D. dissertation, Univ. of Manchester Inst. of Science and Technology.

Lang, T. J., W. A. Lyons, S. A. Rutledge, J. D. Meyer, D. R. MacGorman, and S. A. Cummer (2010), Transient luminous events above two mesoscale convective systems: Storm structure and evolution, J. Geophys. Res., 115, A00E22, doi:10.1029/2009JA014500.
Lang, T. J., J. Li, W. A. Lyons, S. A. Cummer, S. A. Rutledge, and D. R. MacGorman (2011), Transient luminous events above two mesoscale convective systems: Charge moment change analysis, $J$. Geophys. Res., 116, A10306, doi:10.1029/2011JA016758.

Li, J., S. A. Cummer, W. A. Lyons, and T. E. Nelson (2008), Coordinated analysis of delayed sprites with high-speed images and remote electromagnetic fields, J. Geophys. Res., 113, D20206, doi:10.1029/ 2008JD010008.

Li, J., S. A. Cummer, G. Lu, and L. Zigoneanu (2012), Charge moment change and lightning-driven electric fields associated with negative sprites and halos, J. Geophys. Res., 117, A09310, doi:10.1029/ 2012JA017731.

Liu, N. Y., and V. P. Pasko (2004), Effects of photo-ionization on propagation and branching of positive and negative streamers in sprites, J. Geophys. Res., 109, A04301, doi:10.1029/2003JA010064.

Lu, G., S. A. Cummer, J. Li, F. Han, R. J. Blakeslee, and H. J. Christian (2009), Charge transfer and in-cloud structure of large-charge-moment positive lightning strokes in a mesoscale convective system, Geophys. Res. Lett., 36, L15805, doi:10.1029/2009GL038880.

Lu, G., W. P. Winn, and R. G. Sonnenfeld (2011), Charge transfer during intracloud lightning from a time-dependent multi-dipole model, J. Geophys. Res., 116, D03209, doi:10.1029/2010JD014495.

Lyons, W. A. (1994), Characteristics of luminous structures in the stratosphere above thunderstorms as imaged by low-light video, Geophys. Res. Lett., 21(10), 875-878, doi:10.1029/94GL00560.

Lyons, W. A. (1996), Sprite observations above the U.S. High Plains in relation to their parent thunderstorm systems, J. Geophys. Res., 101(D23), 29,641-29,652.

Lyons, W. A., T. Nelson, E. R. Williams, S. A. Cummer and M. A. Stanley (2003), Characteristics of sprite-producing positive cloud-to-ground lightning during the 19 July STEPS mesoscale convective systems, Mon. Weather Rev., 131, 2417-2427.

Lyons, W. A., M. A. Stanley, J. D. Meyer, T. E. Nelson, S. A. Rutledge, T. L. Lang, and S. A. Cummer (2009), The meteorological and electrical structure of TLE-producing convective storms, in Lightning: Principles, Instruments and Applications, edited by H. D. Betz et al., pp. 389-417, Springer Science Business Media B.V., New York, doi:10.1007/978-1-4020-9079-017.

MacGorman, D. R., et al. (2008), TELEX: The Thunderstorm Electrification and Lightning Experiment, Bull. Am. Meteorol. Soc., 89, 997-1013, doi:10.1175/2007BAMS2352.1.

Maggio, C., L. Coleman, T. Marshall, M. Stolzenburg, M. Stanley, T. Hamlin, P. Krehbiel, W. Rison, and R. Thomas (2005), Lightning initiation locations as a remote sensing tool of large thunderstorm electric field vectors, J. Atmos. Ocean. Tech., 22(7), 1059-1068, doi:10.1175/ JTECH1750.1.

Marshall, T. C., and W. D. Rust (1993), Two types of vertical electrical structures in stratiform precipitation of mesoscale convective systems, Bull. Am. Meteorol. Soc., 74, 2159-2170.

Marshall, T. C., M. Stolzenburg, W. D. Rust, E. R. Williams, and R. Boldi (2001), Positive charge in the stratiform cloud of a mesoscale convective system, J. Geophys. Res., 106(D1), 1157-1163, doi:10.1029/ 2000JD900625.

Marshall, R. A., U. S. Inan, and W. A. Lyons (2007), Very low frequency sferic bursts, sprites, and their association with lightning activity, $J$. Geophys. Res., 112, D22105, doi:10.1029/2007JD008857.

Mazur, V., X.-M. Shao, and P. R. Krehbiel (1998), "Spider" lightning in intracloud and positive cloud-to-ground flashes, J. Geophys. Res., 103(D16), 19,811-19,822, doi:10.1029/98JD02003.

McHarg, M. G., R. K. Haaland, D. Moudry, and H. C. Stenbaek-Nielsen (2002), Altitude-time development of sprites, J. Geophys. Res., 107(A11), 1364, doi:10.1029/2001JA000283.

Morrow, R., and T. R. Blackburn (2002), The stepped nature of lightning, and the upward connecting streamer, J. Phys. D: Appl. Phys., 35, L69-L73.

Neubert, T., T. H. Allin, H. Stenbaek-Nielsen, and E. Blanc (2001), Sprites over Europe, Geophys. Res. Lett., 28, 3585-3588.

Ohkubo, A., H. Fukunishi, Y. Takahashi, and T. Adachi (2005), VLF/ELF sferic evidence for in-cloud discharge activity producing sprites, Geophys. Res. Lett., 32, L04812, doi:10.1029/2004GL021943.

Pasko, V. P., U. S. Inan, T. F. Bell, and Y. N. Taranenko (1997), Sprites produced by quasi-electrostatic heating and ionization in the lower ionosphere, J. Geophys. Res., 102(A3), 4529-4561, doi:10.1029/96JA03528.

Pasko, V. P., U. S. Inan, and T. F. Bell (1998a), Spatial structure of sprites, Geophys. Res. Lett., 25(12), 2123-2126, doi:10.1029/98GL01242.

Pasko, V. P., U. S. Inan, T. F. Bell, and S. C. Reising (1998b), Mechanism of ELF radiation from sprites, Geophys. Res. Lett., 25(18), 3493-3496, doi:10.1029/98GL02631.

Pasko, V. P., Y. Yair, and C. Kuo (2011), Lightning related transient luminous events at high altitude in the Earth's atmosphere: 


\section{LU ET AL.: SPRITE TRIANGULATION NEAR OKLMA}

Phenomenology, mechanisms and effects, Space Sci. Rev., 168, doi:10.1007/s11214-011-9813-9.

Pessi, A., S. Businger, K. L. Cummins, N. W. S. Demetriades, M. Murphy, and B. Pifer (2009), Development of a long-range lightning detection network for the Pacific: Construction, calibration, and performance, J. Atmos. Ocean. Tech., 26, 145-166.

Picone, J. M., J. P. Boris, J. R. Greig, M. Raleigh, and R. F. Fernsler (1981), Convective cooling of lightning channels, J. Atmos. Sci., 38, 2056-2062.

Proctor, D. E. (1971), A hyperbolic system for obtaining VHF radio pictures of lightning, J. Geophys. Res., 76, 1478-1489.

Qin, J., S. Celestin, and V. P. Pasko (2011), On the inception of streamers from sprite halo events produced by lightning discharges with positive and negative polarity, J. Geophys. Res., 116, A06305, doi:10.1029/2010JA016366.

Rairden, R. L., and S. B. Mende (1995), Time resolved sprite imagery, Geophys. Res. Lett., 22(24), 3465-3468, doi:10.1029/95GL03332.

Raizer, Y. P., G. M. Milikh, M. N. Shneider, and S. V. Novakovski (1998), Long streamers in the upper atmosphere above thundercloud, J. Phys. Appl. Phys., 31, 3255-3264.

Rakov, V. A., D. E. Crawford, K. J. Rambo, G. H. Schnetzer, M. A. Uman, and R. Thottappillil (2001), $M$-component mode of charge transfer to ground in lightning discharges, J. Geophys. Res., 106(D19), 22,817-22,831, doi:10.1029/2000JD000243.

Reising, S. C., U. S. Inan, T. F. Bell, and W. A. Lyons (1996), Evidence for continuing current in sprite-producing cloud-to-ground lightning, Geophys. Res. Lett., 23, 3639-3642.

Rison, W., R. J. Thomas, P. R. Krehbiel, T. Hamlin, and J. Harlin (1999), A GPS-based three-dimensional lightning mapping system: Initial observations in central New Mexico, Geophys. Res. Lett., 26, 3573-3576.

Rodger, C. J. (1999), Red sprites, upward lightning, and VLF perturbations, Rev. Geophys., 37(3), 317-336, doi:10.1029/1999RG900006.

Rust, W. D., D. R. MacGorman, and R. T. Arnold (1981), Positive cloudto-ground lightning flashes in severe storms, Geophys. Res. Lett., 8(7), 791-794, doi:10.1029/GL008i007p00791.

Rust, W. D., et al. (2005), Inverted-polarity electrical structures in thunderstorms in the Severe Thunderstorm Electrification and Precipitation Study (STEPS), Atmos. Res., 76(1-4), 247.

Rycroft, M. J., and R. G. Harrison (2011), Electromagnetic atmosphereplasma coupling: The global atmospheric electric circuit, Space Sci. Rev., 168, L12811, doi:10.1007/s11214-011-9830-8.

Saba, M. M. F., L. Z. S. Campos, E. P. Krider, and O. Pinto Jr. (2009), High-speed video observations of positive ground flashes produced by intracloud lightning, Geophys. Res. Lett., 36, L12811, doi:10.1029/ 2009GL038791.

São Sabbas, F. T., D. D. Sentman, E. M. Wescott, O. Pinto Jr., O. Mendes Jr., and M. J. Taylor (2003), Statistical analysis of space-time relationships between sprites and lightning, J. Atmos. Sol. Terr. Phys., 65, 525-535.

Sentman, D. D., and E. M. Wescott (1993), Observations of upper atmospheric optical flashes recorded from an aircraft, Geophys. Res. Lett., 20(24), 2857-2860, doi:10.1029/93GL02998.

Sentman, D. D., E. M. Wescott, D. L. Osborne, D. L. Hampton, and M. J. Heavner (1995), Preliminary results from the Sprites94 Aircraft Campaign: 1. Red sprites, Geophys. Res. Lett., 22(10), 1205-1208, doi:10.1029/95GL00583.

Sentman, D. D., et al. (2003), Simultaneous observations of mesospheric gravity waves and sprites generated by a midwestern thunderstorm, $J$. Atmos. Sol. Terr. Phys., 65, 537-550.

Smith, D., X. Shao, D. N. Holden, C. T. Rhodes, M. Brook, P. R. Krehbiel, M. Stanley, W. Rison, and R. J. Thomas (1999), A distinct class of isolated intracloud lightning discharges and their associated radio emissions, J. Geophys. Res., 104, 4189-4212.

Soula, S., et al. (2010), Characteristics and conditions of production of transient luminous events observed over a maritime storm, J. Geophys. Res., 115, D16118, doi:10.1029/2009JD012066.

Stanley, M. A. (2000), Sprites and their parent discharges, Ph. D. dissertation, New Mexico Inst. of Mining and Technology.

Stanley, M., P. R. Krehbiel, M. Brook, C. Moore, W. Rison, and B. Abrahams (1999), High speed video of initial sprite development, Geophys. Res. Lett., 26(20), 3201-3204, doi:10.1029/1999GL010673.
Stanley, M., M. Brook, P. Krehbiel, and S. A. Cummer (2000), Detection of daytime sprites via a unique sprite ELF signature, Geophys. Res. Lett., 27(6), 871-874, doi:10.1029/1999GL010769.

Stolzenburg, M., W. D. Rust, B. F. Smull, and T. C. Marshall (1998), Electrical structure in thunderstorm convective regions: 1. Mesoscale convective systems, J. Geophys. Res., 103, 14,059-14,078.

Suzuki, T., M. Hayakawa, Y. Matsudo, and K. Michimoto (2006), How do winter thundercloud systems generate sprite-inducing lightning in the Hokuriku area of Japan?, Geophys. Res. Lett., 33, L10806, doi:10.1029/2005GL025433.

Suzuki, T., Y. Matsudo, T. Asano, M. Hayakawa, and K. Michimoto (2011), Meteorological and electrical aspects of several winter thunderstorms with sprites in the Hokuriku area of Japan, J. Geophys. Res., 116, D06205, doi:10.1029/2009JD013358.

Taylor, M. J., et al. (2008), Rare measurements of a sprite with halo event driven by a negative lightning discharge over Argentina, Geophys. Res. Lett., 35, L14812, doi:10.1029/2008GL033984.

Thomas, R. J., P. R. Krehbiel, W. Rison, T. Hamlin, J. Harlin, and D. Shown (2001), Observations of VHF source powers radiated by lightning, Geophys. Res. Lett., 28(1), 143-146.

Thomas, R. J., P. R. Krehbiel, W. Rison, S. J. Hunyady, W. P. Winn, T. Hamlin, and J. Harlin (2004), Accuracy of the Lightning Mapping Array, J. Geophys. Res., 109, D14207, doi:10.1029/2004JD004549.

Valdivia, J. A., G. Milikh, and K. Papadopoulos (1997), Red sprites: Lightning as a fractal antenna, Geophys. Res. Lett., 24(24), 3169-3172, doi:10.1029/97GL03188.

Vaughan, Jr., O. H., R. J. Blakeslee, W. L. Boeck, B. Vonnegut, M. Brook, and J. McKune Jr. (1992), A cloud-to-space lightning as recorded by the space shuttle payload-bay TV cameras, Mon. Weather Rev., 120, 1459-1461.

van der Velde, O. A., Á. Mika, S. Soula, C. Haldoupis, T. Neubert, and U. S. Inan (2006), Observations of the relationship between sprite morphology and in-cloud lightning processes, J. Geophys. Res., 111, D15203, doi:10.1029/2005JD006879.

van der Velde, O. A., J. Montanyà, S. Soula, N. Pineda, and J. Bech (2010), Spatial and temporal evolution of horizontally extensive lightning discharges associated with sprite-producing positive cloud-to-ground flashes in northeastern Spain, J. Geophys. Res., 115, A00E56, doi:10.1029/ 2009JA014773.

Warner, T. A., K. L. Cummins, and R. E. Orville (2012), Upward lightning observations from towers in Rapid City, South Dakota and comparison with National Lightning Detection Network data, 2004-2010, J. Geophys. Res., 117, D19109, doi:10.1029/2012JD018346.

Wescott, E. M., H. C. Stenbaek-Nielsen, D. D. Sentman, M. J. Heavner, D. R. Moudry, and F. T. São Sabbas (2001), Triangulation of sprites, associated halos and their possible relation to causative lightning and micrometeors, J. Geophys. Res., 106, 10,467-10,477, doi:10.1029/ 2000JA000182.

Williams, E. R. (1998), The positive charge reservoir for sprite-producing lightning, J. Atmos. Sol. Terr. Phys., 60, 689-692.

Winckler, J. R. (1995), Further observations of cloud-ionosphere electrical discharges above thunderstorms, J. Geophys. Res., 100(D7), 14,335-14,345, doi:10.1029/95JD00082.

Winckler, J. R., W. A. Lyons, T. E. Nelson, and R. J. Nemzek (1996), New high-resolution ground-based studies of sprites, J. Geophys. Res., 101(D3), 6997-7004, doi:10.1029/95JD03443.

Winn, W. P., C. B. Moore, and C. R. Holmes (1981), Electric field structure in an active part of a small, isolated thundercloud, J. Geophys. Res., 86(C2), 1187-1193.

Wu, T., W. Dong, Y. Zhang, and T. Wang (2011), Comparison of positive and negative compact intracloud discharges, J. Geophys. Res., 116, D03111, doi:10.1029/2010JD015233.

Yair, Y., et al. (2004), New observations of sprites from the space shuttle, $J$. Geophys. Res., 109, D15201, doi:10.1029/2003JD004497.

Yashunin, S. A., E. A. Mareev, and V. A. Rakov (2007), Are lightning $M$ components capable of initiating sprites and sprite halos?, J. Geophys. Res., 112, D10109, doi:10.1029/2006JD007631.

Zabotin, N. A., and J. W. Wright (2001), Role of meteoric dust in sprite formation, Geophys. Res. Lett., 28(13), 2593-2596, doi:10.1029/2000GL012699. 